\title{
A method for analysis of nuisance dust from integrated steel works: chemical and mineralogical characteristics of contributing sources
}

\author{
James A. Small ${ }^{1}$ D, Corrie J. G. van Hoek , Katrin Schollbach 1,2, Elmira Moosavi-Khoonsari 1,4,
} Frank J. L. van der Does ${ }^{1}$, Stefan Melzer ${ }^{1}$, Tako P. R. de Jong ${ }^{1}$, Tilly de Bie ${ }^{1}$, Rob A. Versfeld ${ }^{1}$, Michiel de Roo ${ }^{3}$ and Sieger R. van der Laan ${ }^{1,2^{*}}$

\begin{abstract}
Background: Integrated steelmaking is known to emit coarse airborne 'nuisance' dust (10-100 $\mu \mathrm{m})$ to the production site and in the local environs. We present a method to quantitatively analyse the provenance, mineralogical and chemical attributes of the constituent particles in nuisance dust related to the integrated steelworks of Tata Steel, IJmuiden, the Netherlands. The dust is characterised per particle, using scanning electron microscopy with energydispersive spectrometry (SEM-EDS) microanalysis, and in bulk with quantitative X-ray diffraction (XRD) analysis. Based on mineralogical characteristics, particles in the dust are sorted into populations that can be related in detail to industrial processes and subsequent atmospheric weathering influence. The method is illustrated by application to a nuisance dust complaint sample from the neighbouring town Wijk aan Zee containing a large contribution of several dust sources from the integrated steelworks.
\end{abstract}

Results: Besides a background contribution from urban and natural dust, diverse sources from the integrated steelworks are identified in the nuisance dust sample, derived from coke-making, iron-ore agglomeration processes and blast furnace ironmaking, steelmaking slag processing, process fluxes, as well as steelmaking refractory materials. The most voluminous of these in the sample are directly verified by comparison with a set of reference source materials. The abundances, mineralogical and chemical attributes of the various dust particle populations in the sample are quantitatively examined including, specifically, the occurrence of the potentially toxic elements $\mathrm{Mn}$ and $\mathrm{V}$. These elements occur with highest concentrations in dust derived from steelmaking converter slag: $V$ is housed in dilute form (solid solution) in the phases di-calcium silicate and brownmillerite, and Mn chiefly in Mg-Fe-oxide (Mg-wustite $((\mathrm{Mg}, \mathrm{Mn}, \mathrm{Fe}) \mathrm{O})$ and its oxidation product $\left.\left((\mathrm{Mg}, \mathrm{Mn}, \mathrm{Fe})(\mathrm{Fe}, \mathrm{Mn})_{2} \mathrm{O}_{4}\right)\right)$.

Conclusions: By treating nuisance dust as a particulate, multi-phase, multi-source material, the outlined method provides crucial information for toxicological evaluation and for mitigation of emissions, which is not obtainable by bulk chemical analyses alone. It also helps address the lack of adequate monitoring options for deposits of nuisance dust from integrated steel production, necessary to evaluate the relationship between deposition and monitored emissions that are regulated by the European Industrial Emissions Directive and by local permits based on this legislation.

\footnotetext{
${ }^{*}$ Correspondence: sieger.van-der-laan@tatasteeleurope.com

${ }^{1}$ Tata Steel Europe, P.O. Box 10.000, 1970 CA IJmuiden, The Netherlands

Full list of author information is available at the end of the article
} in this article are included in the article's Creative Commons licence, unless indicated otherwise in a credit line to the material. If material is not included in the article's Creative Commons licence and your intended use is not permitted by statutory regulation or exceeds the permitted use, you will need to obtain permission directly from the copyright holder. To view a copy of this licence, visit http://creativeco mmons.org/licenses/by/4.0/. 
Keywords: Steelmaking, Coarse airborne dust, Nuisance dust, Characterisation, Analysis, X-ray diffraction, Microscopy, Mineralogy, Vanadium, Manganese

\section{Background}

The dispersion of coarse airborne dust $(10-100 \mu \mathrm{m})$ is experienced as a nuisance by those affected, as it soils surfaces where it is deposited, giving rise to the term 'nuisance dust' (used hereinafter to refer to this size fraction of dust). More importantly, depending on the nature of this nuisance dust, it can pose health- and environmental risks and damage property. Hence, the composition and extent of exposure to this dust need to be evaluated, certainly in the vicinity of industrial activity. Monitoring of nuisance dust is currently neither standardised nor widely practiced $[1,2]$ unlike for the finer dust fractions PM10 (particulate matter $<10 \mu \mathrm{m}$ in diameter) and PM2.5 $(<2.5 \mu \mathrm{m})$ as per European Ambient Air Directive $[3,4]$ and standard EN 12341:2014 [5].

The health risks posed by nuisance dust $(>10 \mu \mathrm{m})$ are generally considered lower than those of inhalable PM10 and PM2.5 dust; however, dermal and oral exposure routes for nuisance dust ought to be considered. Nuisance dust can be inhaled but does not travel far beyond the uppermost respiratory tract, the oral/nasal cavity and larynx, into the tracheobronchial airway region [6]. By mucociliary clearance and coughing, the particles are brought back up to the oral cavity and they are subsequently swallowed $[7,8]$. If soluble along the digestive tract, the oral/nasal cavity, or in the lungs, dust constituents can pose health risks to the recipient [6]. Health risk evaluation should involve relevant particle-related metrics for dosimetry, such as solubility, particle count, size, surface area and composition [9].

Risks associated with dust contributions to the local soil should be assessed based on the dust constituents' bio-availability in the depositional environment [10-12]. To evaluate the risks associated both with digestion and soil contamination, it is insufficient to know only the inventory of elements present and their concentrations. Rather, the nature of the compounds needs to be known to evaluate the health and environmental impact of the dust.

This article presents a method to analyse nuisance dust regarding its constituent (mineral-)compounds and diverse contributing source materials. Our study relates specifically to integrated steel production where dust is associated with many processes, such as handling of raw materials (ores, fluxes and coals) and by-product streams (slags), high-temperature agglomeration (coke-making, sinter- and pellet production), as well as blast furnace ironmaking and steelmaking itself, see also, e.g. the study of Hleis et al. [13]. In the production environment, the risk of dispersal of nuisance dust is exacerbated by strong thermal updrafts associated with the processes at steelworks, which transports large particles to high elevations in open air with ample opportunity for dispersal by winds.

For risk assessment and effective mitigation, it is necessary to distinguish various dust types and their sources $[14,15]$. A methodology to do this has been developed at Tata Steel in IJmuiden, the Netherlands, using scanning electron microscopy and energy-dispersive spectrometry (SEM-EDS) and largely automated data processing. Based on mineralogical characteristics, the detected particles (grains) in a sample are classified under different populations, linked where possible with verified reference source materials. The abundances and chemical and mineralogical characteristics of these populations are then quantitatively analysed. This approach for analysing nuisance dust samples, and the type of information it yields, is discussed and illustrated here by application to a nuisance dust complaint sample from the town Wijk aan Zee (the Netherlands) containing a large contribution of several verified dust sources from the neighbouring Tata Steel IJmuiden integrated steelworks.

\section{European legal framework for dust emissions}

Dust emissions from industry in Europe are regulated by the Industrial Emission Directive [16]. According to this directive, industry applies for a permit providing the information on process and installation necessary for a country's local authority to set the permit conditions. The issued permit includes all the measures necessary to achieve a high level of protection for the environment as a whole (air, water and soil) set on the basis of Best Available Techniques (BAT) for emission prevention [16-18] with stipulation that the installation is properly operated. A permit includes emission limit values, or equivalent parameters or technical measures, and monitoring requirements. Limits for particulate matter in air are provided by the European Air Quality legislation [19]. Thus, with permits, the emissions from industrial production are regulated for a total mass allowance of emitted dust, and by legislation for concentration levels of PM10 and PM2.5, as well as for levels of arsenic, cadmium, mercury, nickel and polycyclic aromatic hydrocarbons.

In practice, for the integrated steel works of Tata Steel at IJmuiden, The Netherlands, the environmental permit limits the total emission of dusts from smokestacks as 
well as from roofs/building tops with a maximum value currently set at 1750 ton/y total suspended particles (TSP) with separately defined limits for each process and operational dust scrubbing technique following BAT. The smokestack/roof-top emissions are quantified by continuous or regularly dust and PM10 monitoring. In 2019, the IJmuiden site emitted 688 ton TSP from these point sources, of which 481 ton PM10.

In addition, regarding nuisance dust, the European BREF Emissions from Storage [20] dictates the measures for raw materials, scrap and slag stockyards. In this regard, the Dutch Activities Decree applies to storage, handling and transportation. Currently, the permit is set for a maximum emission allowance of 1850 ton/y of total dust for the IJmuiden site. For these emissions, a methodology for quantification is used based on emission factors, size of storage areas, and activity intensity. Based on monitoring data, it is estimated that the site IJmuiden in 2019 emitted 1193 ton TSP from these open sources, of which 230 ton PM10. Emissions from the processing of steelmaking slags by a contracting company are regulated on a separate permit.

Total emissions (point, diffuse and open) from the IJmuiden site are publicly available information. PM10 is reported in the European Register EPRTR [21], with most recent entries from 2017. The TSP is reported in the Tata Steel Sustainability Report [22], with the most recent issue from 2018. Detailed data (Annual Emission Reports/Emissiejaarverslag) are reported to the Environmental Authorities in the Netherlands.

\section{Rationale of nuisance dust characterisation}

Nuisance dust is a particulate material containing particles derived potentially from multiple diverse sources-industrial, urban, agricultural and natural. Its characteristics reflect the emission potential of the contributing source areas [23], the transfer efficiency of these, and the retention/remobilisation tendency of particles after their initial deposition. Characterisation of nuisance dust must provide relevant information about its constituent particles and (sub-)populations of these that correspond to identifiable sources, preferably verifiable with reference source materials. The most relevant information concerns 1) establishing the provenance of particle populations, which is critical for mitigating emissions, and 2) evaluating environmental and health risks associated with these particles.

Commonly, the chemical composition of a whole particle is measured in SEM-EDS studies on dust [24-26]. This reflects, but does not explicitly describe, the combination of (mineral-)phases present at its surface, which can be (heavily) altered by weathering reactions. Moreover, an individual particle is a sub-sample commonly too small to be representative of the bulk chemical composition of a multi-phase source material. For these reasons, analysing the (mineral-)phase constituents of particles is preferable for establishing provenance since the chance of encountering a diagnostic combination of phases in a small and potentially weathered particle is still high. It is also preferable for understanding the form of binding of elements in mineral phases, which is crucial for establishing elements' bio-availability $[9,27]$.

To characterise both the (surface-) chemistry and mineralogy of dust particles, our approach combines SEMEDS spectral imaging (SI) and an in-house-developed software package, PARC (PhAse Recognition and Characterisation) [28], to convert SI data into phase distribution maps. The phase distribution maps have a spatial resolution of between 1 and $2 \mu \mathrm{m}$ (depending on settings for data acquisition) and reflect the surface mineralogy of the dust particles since the SEM electron beam generates characteristic element X-ray signal only to very limited depths of a few $\mu \mathrm{m}$ into the sample [29]. Quantitative X-ray diffraction (QXRD) analysis of the dust sample (as mounted for SEM-EDS analysis) is used to provide an independent, complementary characterisation of the crystalline phases present in the bulk material, albeit not spatially resolved. The definition of phases in QXRD is crystallographic; whereas in the SEM-EDS-SIPARC (hereinafter simply PARC) approach phases are chemically defined. Certain phases which are chemically difficult to separate with the SEM-EDS-SI approach, such as the Fe-oxides hematite and magnetite, are easily distinguishable and quantifiable with QXRD. Conversely, the QXRD analyses cannot identify and quantify the abundances of different amorphous phases which are chemically identifiable with SEM-EDS, nor very lowabundance phases (with detection limits of $0.1 \mathrm{wt} \%$ to 5 wt\% depending on the crystal structure and crystal statistics). Combining techniques ultimately provides a useful cross-verification of the abundance of certain phases or phase-groups.

An additional strength of the PARC approach is that it can readily detect even extremely low-abundance phases occurring in a dust sample as long as (1) the phase is coarse enough to be spatially resolved by the measurements and (2) the phase can be defined and detected based on a unique combination of its own major constituent elements (see the section "Phase distribution maps from spectral imaging data" for more detail). Such trace phases may contain high concentrations of elements that are present only at very low concentration in the bulk sample. The detection limit with EDS of an element in a phase varies with matrix material (e.g. oxide/metallic etc.), surface topography and analytical conditions, but as a rule of thumb $\sim 0.1 \mathrm{wt} \%$ is widely accepted. The PARC 
approach is, therefore, able to detect the occurrence of low-concentration elements in the bulk where these are present in a concentration of $>\sim 0.1 \mathrm{wt} \%$ in one or more distinctive phases, which provides valuable information on the speciation of such elements.

The approach described here is, in short, to detect individual dust particles and to sort these into interpretable populations based on characteristic (mineralogical) phase combinations by processing SEM-EDS-SI measurements with PARC. This yields detailed, quantitative mineralogical, (phase-)chemical and morphological information on individual particles and particle populations and the abundances of these populations in the bulk sample are quantified.

\section{Materials and methods}

\section{Sample collection and preparation}

Nuisance dust samples are collected related to complaints on- and off-site. Regularly cleaned surfaces such as car panels, windowsills and garden furniture typically form the substrate on which nuisance dust is noticed. Dust is collected from these surfaces with a fine brush and stored in a glass vial for transport to the lab. Samples constitute normally at most a few milligrams of dust. In the lab, the dust is sprinkled onto a double-sided adhesive conductive carbon disc, mounted on an aluminium stub. All subsequent analyses are performed on the original particles, i.e. particles are not sectioned and polished. The primary reasons for this are (1) the relative speed and ease of preparation, given the extremely small quantities of available material; (2) the fact that the particles are fully exposed, enabling shape and size quantification; and (3) the ability to examine the surface of particles, including thin covering layers which are barely resolvable in cross-section. Up to 26 dust samples can be combined in a sample holder with fixed positions for viewing. This facilitates automation and cross-correlation of data acquired on the same mounted sample using multiple analytical techniques such as 3D light optical microscopy, SEM-EDS-SI-PARC and XRD analysis.

Much of the discussion of the dust characterisation approach in this article is illustrated with a nuisance dust sample collected 26/01/2020 as part of an ongoing timeseries sampling campaign at a residential location in Wijk aan Zee, near the IJmuiden Tata Steel site. This specific sample contains a very high contribution of several dust sources from the integrated steelworks which are verified by comparison with reference source materials and which are encountered consistently in other nuisance dust complaint samples.

\section{Raw data acquisition 3D light optical microscopy}

Light optical microscopy (LOM) is performed on samples directly after mounting on an aluminium stub using a ZEISS SmartZoom5 (PlanApo D 5.0x/0.3 objective, with optical resolution of $0.92 \mu \mathrm{m})$. Since the particles have considerable topography, Z-stack imagery is acquired to ensure sharpness at different focal levels, referred to hereafter as 3D-LOM. Such an image is shown in Fig. 1a for an exemplary nuisance dust sample.

\section{SEM and EDS spectral imaging}

Samples are coated with carbon prior to SEM analysis. Back-scattered electron (BSE) images and spectral images (SI) are normally collected for several adjacent fields (typically $3 \times 3$ ) of $1024 \times 768$ (BSE) and $512 \times 384$ (SI) pixels with a pixel step-size of $0.8 \mu \mathrm{m}$, for BSE, and $1.6 \mu \mathrm{m}$ for SI, although higher resolutions can be obtained. Fig. 1b shows the BSE image of the same area as the LOM image in Fig. 1a.

The SI data acquisition for the analyses reported here was performed with a JEOL 7001 FEG-SEM instrument equipped with a Thermo Fisher Scientific microanalysis system, running Pathfinder 1.3 software (same manufacturer), with two SDD/EDS detectors (crystal area 30 $\mathrm{mm}^{2}$ each) positioned roughly diametrically opposite one another. This detector configuration is essential for SI data collection of 3D objects such as dust particles because EDS detectors are typically mounted at a $35^{\circ}$ take-off angle, and signal is obtained only from the parts of the object's surface facing towards the detector. With detectors viewing from two diametrically opposite positions and combining the signals, this mitigates to a large degree the signal-shadow effects from sample topography. An accelerating voltage of $15 \mathrm{kV}$ and beam current of $10 \mathrm{nA}$ were used, with a total acquisition time per field of $30 \mathrm{~min}$.

Quantitative chemical analyses were derived from EDS spectra with the Pathfinder 1.3 software in standardless mode, using the inbuilt filter fit method for peakfitting and PROZA (Phi-Rho-Z) correction method.

\footnotetext{
(See figure on next page.)

Fig. 1 Four correlated images of exemplary nuisance dust sample: a LOM, b SEM-BSE, c PARC groups (phase map), d grain populations. Keys show colour coding for $\mathbf{c}$ PARC groups in Table 1 and $\mathbf{d}$ PARC grain populations in Table 3. Area proportions (area \%) are for the whole analysed area as shown. The \{empty spectra\} count for image $\mathbf{c}$ includes the background pixels of the sample holder. Area percentages for $\mathbf{d}$ are normalised to $100 \%$ excluding the background shown in black. Note, a small number of loosely mounted particles visible in a had physically moved prior to acquisition of images $\mathbf{b}-\mathbf{d}$. Full resolution images and accompanying tabulated data given in Additional file 1: D
} 


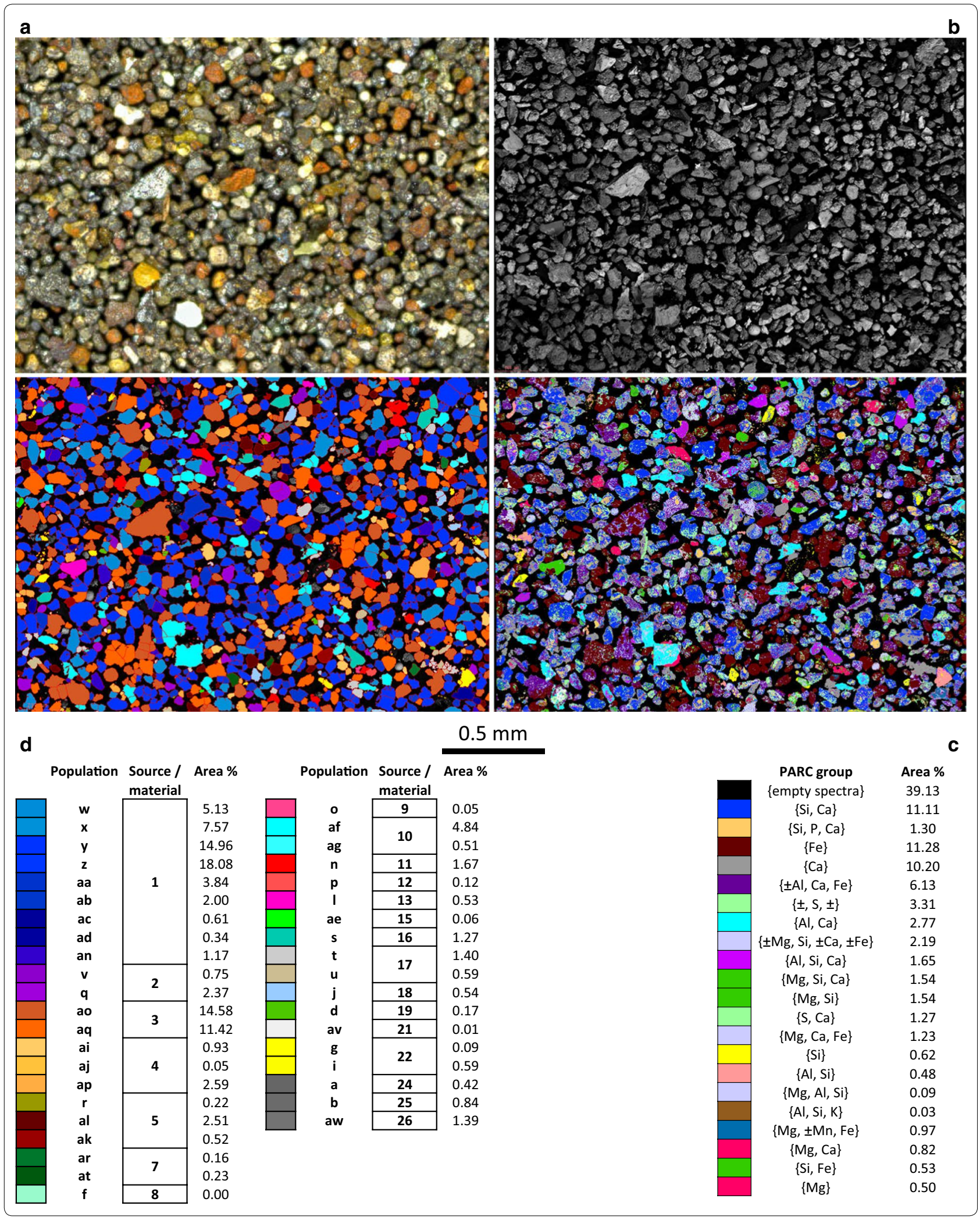



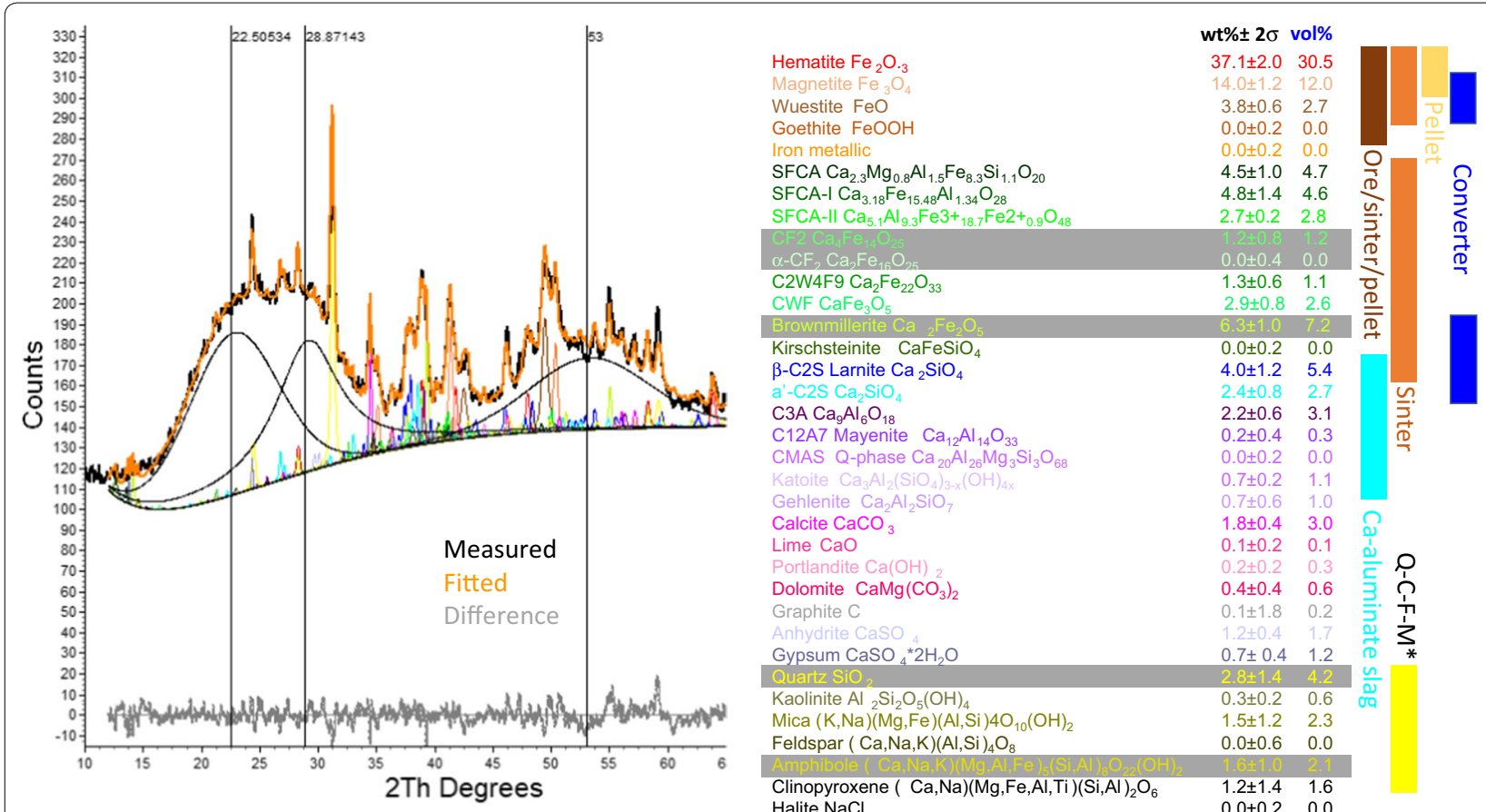

Fig. 2 Results of quantitative XRD analysis of example nuisance dust sample (as shown in Fig. 1), showing raw and modelled diffraction pattern, left, and quantitative phase analysis, right. Phase proportions are shown in terms of mass (wt\%, with $2 \sigma$ uncertainty) and volume (vol\%). Coloured bars on right-hand side of table show typical association of phases with key source materials as outlined in Table 2. ${ }^{*} \mathrm{Q}-\mathrm{C}-\mathrm{F}-\mathrm{M}=\mathrm{quartz}-\mathrm{Clay}-$ feldspar-mica source/material category as in Table 2

Element concentrations are quantified and reported using assumed oxide forms (oxygen concentration is not independently analysed). Carbon is excluded from the quantification (note, for the sake of completeness, both carbon and oxygen net count values are reported together with those of the other analysed elements in Additional file 1: F).

\section{QXRD}

Dust samples are analysed with QXRD for crystalline compounds on the same microscopy mount but a larger area of about $4 \mathrm{~mm}^{2}$ is examined. Except for the converter-slag reference dust samples, a Bruker D8 Discover instrument was used with a $2 \mathrm{D}$ position-sensitive area detector (Våntec 500) and $\mathrm{Co} K \alpha$ radiation $(30 \mathrm{kV} / 40 \mathrm{~mA})$ with sample rotation during measurement. In total, three individual frames were recorded to cover a range from 10 to $100^{\circ} 2 \theta$ with a total measurement time of $30 \mathrm{~min}$. The individual frames are merged. The XRD patterns for the converter-slag reference dusts were recorded with Bruker D8 Endeavour diffractometer equipped with position-sensitive detector (Lynxeye $\mathrm{XE}-\mathrm{T})$. The radiation used was $\mathrm{Cu} \mathrm{K} \alpha(40 \mathrm{kV} / 40 \mathrm{~mA})$.

The advantage of this measurement procedure is that more crystals are found in diffraction condition than with a conventional Bragg-Brentano diffractometer. The data are converted into a standard diffraction pattern of angle $(2 \theta)$ vs. intensity as presented in Fig. 2. Phase proportions in weight percent (wt\%) are quantified using the Rietveld approach and subsequently converted into volume percent (vol\%) using phase densities derived from the ICSD database [30] (see Additional file 1: A). Volume percentage provides greater ease of comparison with microscopy images that also represent volumetric information.

\section{Data analysis}

The following sections describe the processing of SEMBSE- and EDS-SI image data with PARC for phase identification, particle detection (segmentation) and subsequent assignment of particles to different populations. A schematic overview of the raw data, processing steps and data output from PARC is shown in Fig. 3.

\section{Phase distribution maps from spectral imaging data}

The PARC software is used to convert spectral imaging (SI) data into phase distribution maps following methods described in more detail in van Hoek et al. [28]. The raw SI dataset contains the EDS spectrum for each pixel in an image field. The software sorts all pixels into groups, hereafter referred to as PARC groups, based on the 


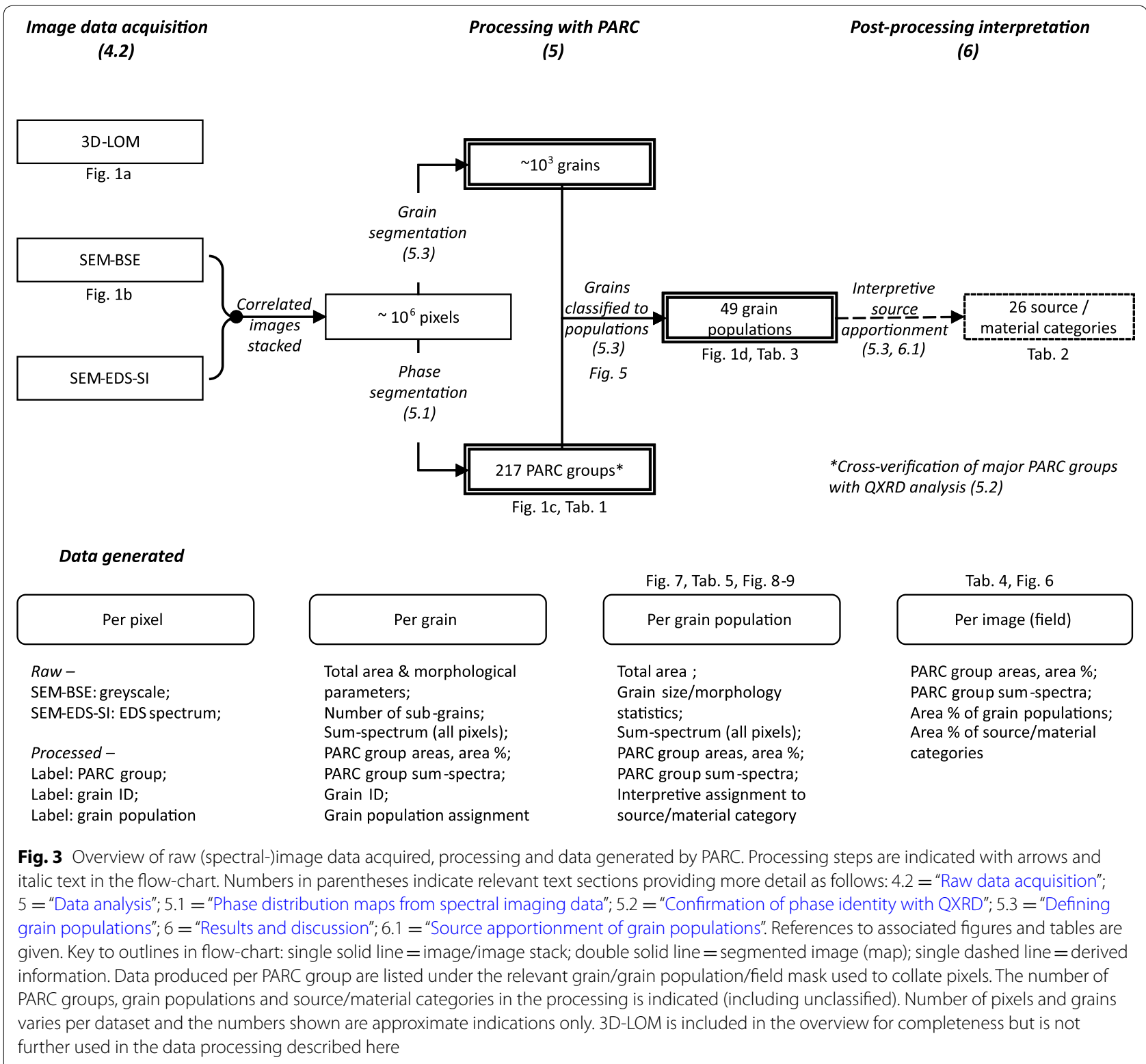

detected combinations of spectral peaks. A peak is registered if its energy and intensity are above user-defined threshold values. The pixel sorting results in groups of unique peak, i.e. element, combinations. The distribution of these groups is shown in a colour-coded phase map (as in the example in Fig. 1c) alongside the SEM backscattered electron (BSE) images (Fig. 1b), for a single field or for multiple stitched fields. Area percentages of all groups are quantified (as displayed in the key to the phase map in Fig. 1c). The relationship between area and volumetric proportions is discussed in the section "Quantification of volumetric contributions".

The naming convention used in this article for PARC groups is $\{p 1, p 2, \ldots, p n\}$, referring to the spectral peaks by which the group is defined, and listed in order of increasing energy, i.e. a purely descriptive label rather than an interpretative one in terms of true mineralogical phases with which the group may correspond. The PARC groups occurring in materials discussed in this article are listed in Table 1 . The chemical composition of a PARC group can be quantified using the sum spectrum of all pixels belonging to the group. Marginal pixels which are bordering with other groups in an image, where their spectrum is likely contaminated by signal from the adjacent phase, can be excluded in the quantification by applying a pixel-erosion filter. The thus-cleaned sum-spectra can be exported by PARC and converted to quantitative chemical analyses as described in "Raw 
Table 1 Selected PARC groups, correspondence with phases detected by XRD and other common phases/mixtures/ artefacts inferred from detailed SEM-EDS analysis

\begin{tabular}{|c|c|c|c|}
\hline PARC group & XRD-PARC overlap & XRD phase & Other common phases/mixtures/artefacts \\
\hline$\{\mathrm{Si}, \mathrm{Ca}\}$ & ${ }^{1} \mathrm{C} 2 \mathrm{~S}$ & Beta-C2S (larnite) & $\begin{array}{l}\text { C3S (hatrurite, or breakdown products thereof); other Ca-silicate phases; } \\
\text { mixed pixels }-\{\mathrm{C} \text {; }\} \text { calcite/lime/portlandite }+\{\text { Si }\} \text { silica }\end{array}$ \\
\hline$\{\mathrm{Si}, \mathrm{P}, \mathrm{Ca}\}$ & & Alpha'-C2S & Extreme P-rich variant: weathering product after C2S \\
\hline \multirow{4}{*}{$\begin{array}{l}\{\mathrm{Fe}\} \\
\{\mathrm{Fe}, \mathrm{Fe}(\mathrm{K} \beta)\}\end{array}$} & \multirow[t]{4}{*}{$\mathrm{FeOx} / \mathrm{FeO}(\mathrm{OH}) / \mathrm{Fe}$} & Hematite & \multirow{7}{*}{$\begin{array}{l}\text { Siderite; Artefact, }\{\mathrm{Fe}, \mathrm{Fe}(\mathrm{K} \beta\}\} \text { pixels used as tracer for iron metallic on } \\
\text { grain/population/sample scale }\end{array}$} \\
\hline & & Magnetite (incl. Mg-ferrite rich) & \\
\hline & & Goethite & \\
\hline & & Iron metallic & \\
\hline \multirow[t]{3}{*}{$\mathrm{Ca}$} & \multirow[t]{3}{*}{ Calcite/lime/portlandite } & Calcite & \\
\hline & & Lime & \\
\hline & & Portlandite & \\
\hline \multirow[t]{7}{*}{$\mathrm{Ca}, \mathrm{Fe}$} & \multirow[t]{7}{*}{ Ca-ferrites } & ${ }^{2}$ SFCA & \multirow{7}{*}{$\begin{array}{l}\text { Note: } S F C A \longrightarrow C W F \text { occur near exclusively in sinter, brownmillerite } \\
\text { C2(A,F) dominantly in converter slag; Mixed pixels— }\{\mathrm{C}\} \text { calcite/lime/ } \\
\text { portlandite }+\{\mathrm{Fe}\} \text { FeOx may occur in poorly reacted pellet/sinter mate- } \\
\text { rial }\end{array}$} \\
\hline & & SFCA-I & \\
\hline & & SFCA-II & \\
\hline & & CF2 & \\
\hline & & alpha-CF2 & \\
\hline & & C2W4F9 & \\
\hline & & CWF & \\
\hline$\{\mathrm{Al}, \mathrm{Ca}, \mathrm{Fe}\}$ & & Brownmillerite $C 2(A, F)$ & \\
\hline \multirow[t]{3}{*}{$\mathrm{Al}, \mathrm{Ca}$} & \multirow[t]{3}{*}{ Ca-aluminates } & $\mathrm{C} 3 \mathrm{~A}$ & \multirow{3}{*}{$\begin{array}{l}\text { Artefact pixels-highly Al-rich brownmillerite C2(A,F) where Fe peak } \\
\text { intensity does not exceed threshold for assignment as }\{\mathrm{Al}, \mathrm{Ca}, \mathrm{Fe}\}\end{array}$} \\
\hline & & C12A7 & \\
\hline & & ${ }^{3}$ CMAS Q-phase & \\
\hline$\{\mathrm{Si}, \mathrm{Ca}, \mathrm{Fe}\}$ & $\begin{array}{l}\text { Kirschsteinite, clinopy- } \\
\text { roxene, amphibole }\end{array}$ & Kirschsteinite & $\begin{array}{l}\text { Mixed pixels- }\{\mathrm{Si}, \mathrm{Ca}\} \mathrm{C} 2 \mathrm{~S}+\{\mathrm{Fe}\} \mathrm{FeOx} \text { or }\{\mathrm{Ca} \text {, Fe }\} \text { Ca-ferrites intergrowth } \\
\text { in sinter }\end{array}$ \\
\hline$\{\mathrm{Mg}, \mathrm{Si}, \mathrm{Ca}, \mathrm{Fe}\}$ & & Clinopyroxene & Mixed pixels \\
\hline$\{\mathrm{Mg}, \mathrm{Si}, \mathrm{Fe}\}$ & & Amphibole & Mixed pixels \\
\hline$\{\mathrm{Mg}, \mathrm{Si}, \mathrm{Ca}\}$ & Monticellite & Monticellite & Clinopyroxene \\
\hline$\{\mathrm{Mg}, \mathrm{Si}\}$ & Forsterite & Forsterite & Orthopyroxene \\
\hline \multirow[t]{2}{*}{$\mathrm{Al}, \mathrm{Si}, \mathrm{Ca}$} & \multirow[t]{2}{*}{ Gehlenite and Katoite } & Katoite & \multirow[t]{4}{*}{ Ca-feldspar (anorthite) } \\
\hline & & Gehlenite & \\
\hline \multirow[t]{2}{*}{$\mathrm{S}, \mathrm{Ca}$} & \multirow[t]{2}{*}{ Gypsum/anhydrite } & Anhydrite & \\
\hline & & Gypsum & \\
\hline$\{ \pm, S, \pm\}$ & - & - & $\begin{array}{l}\text { Diverse sulphates and sulphides; mixed pixels_-sulphates on particle } \\
\text { surfaces }\end{array}$ \\
\hline$\{\mathrm{Si}\}$ & Quartz & Quartz & Amorphous silica; SiC \\
\hline$\{\mathrm{Al}, \mathrm{Si}\}$ & Kaolinite & Kaolinite & Mullite, other alumino-silicates \\
\hline$\{\mathrm{Mg}, \mathrm{Al}, \mathrm{Si}\}$ & Mica & Mica & \\
\hline$\{\mathrm{Al}, \mathrm{Si}, \mathrm{K}\}$ & Feldspar & Feldspar & \\
\hline $\begin{array}{l}\{\mathrm{Mg}, \mathrm{Fe}\} \\
\{\mathrm{Mg}, \mathrm{Mn}, \mathrm{Fe}\}\end{array}$ & Mg-wustite & Mg-wustite & $\begin{array}{l}\text { Mg-ferrite rich spinel solid solution in pellets and sinter; finely intergrown } \\
\text { oxidation products after Mg-wustite in converter slag, including spinel } \\
\text { solid solution (magnetite) }\end{array}$ \\
\hline$\{\mathrm{Mg}, \mathrm{Ca}\}$ & Dolomite & Dolomite & Decarbonation products after dolomite \\
\hline$\{\mathrm{Mg}, \mathrm{Ca}, \mathrm{Fe}\}$ & - & - & $\begin{array}{l}\text { Mixed pixels_ }\{\text { Mg, Fe }\} \text { Mg-wustite }+\{C a, F e\} \text { brownmillerite } C 2(A, F) \text { in } \\
\text { converter slag }\end{array}$ \\
\hline$\{\mathrm{Si}, \mathrm{Fe}\}$ & - & - & $\begin{array}{l}\text { Mixed pixels - }\{\text { Si }\} \text { silica or diverse high-Si silicates }+\{\mathrm{Fe}\} \mathrm{FeO} \text { in pellets } \\
\text { and sinter; much less commonly fayalite }\end{array}$ \\
\hline$\{\mathrm{Mg}\}$ & Periclase/brucite & Periclase/brucite & \\
\hline$\{\mathrm{Mg}, \mathrm{Al}\}$ & - & - & Spinel \\
\hline$\{\mathrm{Mg}, \mathrm{Al}, \mathrm{Si}, \mathrm{Ca}\}$ & - & - & $\begin{array}{l}\text { Blast furnace slag (glassy); other Ca-Mg-Al-silicate glasses; melilite (aker- } \\
\text { manite-gehlenite) }\end{array}$ \\
\hline$\{P, C a\}$ & Apatite & Apatite & \\
\hline$\{ \pm, P, \pm\}$ & - & - & Diverse phosphates/phosphides \\
\hline
\end{tabular}


Table 1 (continued)

\begin{tabular}{|c|c|c|c|}
\hline PARC group & XRD-PARC overlap & XRD phase & Other common phases/mixtures/artefacts \\
\hline$\{\mathrm{Mn}\}$ & & & MnO-rich monoxide \\
\hline$\{\mathrm{Si}, \mathrm{Mn}\}$ & & & Mn-silicate \\
\hline$\{A \mid\}$ & & & Alumina (corundum); aluminium metal \\
\hline$\{\mathrm{Ti}\}$ & & & $\mathrm{TiO} 2$ (rutile) \\
\hline$\{\mathrm{Al}, \mathrm{Si}, \mathrm{Ti}\}$ & & & Ti-Al-silicate \\
\hline$\{\mathrm{Si}, \mathrm{Ti}\}$ & & & Ti-silicate \\
\hline$\{Z n(L a), \pm\}$ & - & - & $\begin{array}{l}\mathrm{ZnO} \text { (zincite); ZnFe-oxide ( } \mathrm{Zn} \text {-ferrite) + other Zn-dominated oxides with } \\
\text { minor elements }\end{array}$ \\
\hline$\{\mathrm{Na}, \mathrm{Cl}\}$ & Halite $(\mathrm{NaCl})$ & Halite ( $\mathrm{NaCl})$ & \\
\hline$\{ \pm, C l, \pm\}$ & - & - & Diverse chlorides; mixed pixels_chlorides on particle surfaces \\
\hline$\{$ empty spectra\} & Graphite & Graphite & All forms of carbon, including sample mounting medium \\
\hline
\end{tabular}

See Fig. 2 for full XRD phase names and nominal chemical formulae. 'Several phases named using cement chemist notation, where formulae are abbreviated with $\mathrm{C}=\mathrm{CaO}, \mathrm{M}=\mathrm{MgO}, \mathrm{A}=\mathrm{Al}_{2} \mathrm{O}_{3}, \mathrm{~S}=\mathrm{SiO}_{2}, \mathrm{~W}=\mathrm{FeO}, \mathrm{F}=\mathrm{Fe}_{2} \mathrm{O}_{3}$. N.B. the following abbreviations are of phase names rather than chemical formulae: ${ }^{2}$ silico ferrite of calcium and aluminium (SFCA) and ${ }^{3} \mathrm{CMAS}$ Q-phase $=\mathrm{Ca}-\mathrm{Mg}-\mathrm{Al}$-Si-oxide Q-phase

data acquisition" section and yield compositions with reasonable correspondence to known phase stoichiometry, sufficient for phase identification. Locally, if two or more phases are finely intergrown on a length-scale smaller than the spatial resolution $(1 \mu \mathrm{m}$ excitation volume), a mixed spectrum is generated that cannot be distinguished from a single phase. Such mixed pixels are nonetheless assigned to a PARC group based on their characteristic peak combination and, with appropriate account taken of this potential artefact, can also be used as a diagnostic feature for particle populations.

With grouping based on peak combinations only, separate phases containing the same major elements in different proportions will not be distinguished and are classified as one PARC group. The possibility exists within PARC to further sub-divide such groups based on continuous variations in element-peak intensity (ratios) using so-called "density plots" [28]. However, with 3D objects like dust particles, these intensities are generally too strongly affected by topography to robustly apply this approach. Hence, the groups here are based purely on element-peak combinations. As a result, there is a bracket of plausible/commonly occurring true phases corresponding with a PARC group within a dust sample or a given particle.

Peaks with energies below $0.9 \mathrm{keV}$ are excluded here when defining PARC groups, due to (1) overlap of the K-line peaks of the light elements $\mathrm{C}, \mathrm{N}, \mathrm{O}$ and $\mathrm{F}$ with the L-line peaks of first series transition elements; and (2) strong absorption effects on low-energy signal due to the topography of the 3D particles. Consequently, no direct distinction is made between carbonates, hydrates, and various oxidation states of elements. The generally much higher intensity of the Fe $K \beta$ peak in spectra measured in (verified) metallic Fe is, however, exploited to help distinguish dust particles rich in metallic Fe as opposed to $\mathrm{FeOx}$.

The thus-defined pixel groups are saved in a PARC group model and our approach is to apply one standard model consistently to all datasets on nuisance dust samples (which may be periodically updated and re-applied to old datasets). All PARC groups with more than $1 \%$ area contribution to any dust particle (grain) population in the exemplary nuisance dust sample are shown in Table 1 (full listing of all PARC groups is given in Additional file 1: D). The spectral image converted to a PARC phase map is given in Fig. 1c.

A large number (around half the total) of PARC groups are defined by the presence of either chlorine-, sulphur-, or phosphorous peaks in addition to other elements. These $\{ \pm, \mathrm{Cl}, \pm\},\{ \pm, \mathrm{S}, \pm\}$ and $\{ \pm, \mathrm{P}, \pm\}$ groups are mostly not identifiable as genuine chemical compounds and they result from a thin layer of contaminant chlorides, sulphates or phosphates on top of a grain, giving mixed spectra.

\section{Confirmation of phase identity with QXRD}

Table 1 shows the interpreted correspondence between PARC groups and phases detected by XRD in the example nuisance dust and in reference source materials (see the section "Reference source materials"). The PARC groups with the highest abundances in these samples all correspond clearly with one or more phases detected by XRD. PARC analyses in the samples shown here, and more generally in our analyses of nuisance dust samples, show higher abundance of certain phases than obtained from quantitative XRD analysis. This is consistently the case for the following PARC groups: $\{\mathrm{Si}, \mathrm{Ca}\}$ and $\{\mathrm{Si}, \mathrm{P}$, Ca\} compared with XRD C2S phases; $\{\mathrm{Ca}\}$ compared with XRD calcite/lime/portlandite; $\{\mathrm{Na}, \mathrm{Cl}\}$ compared 


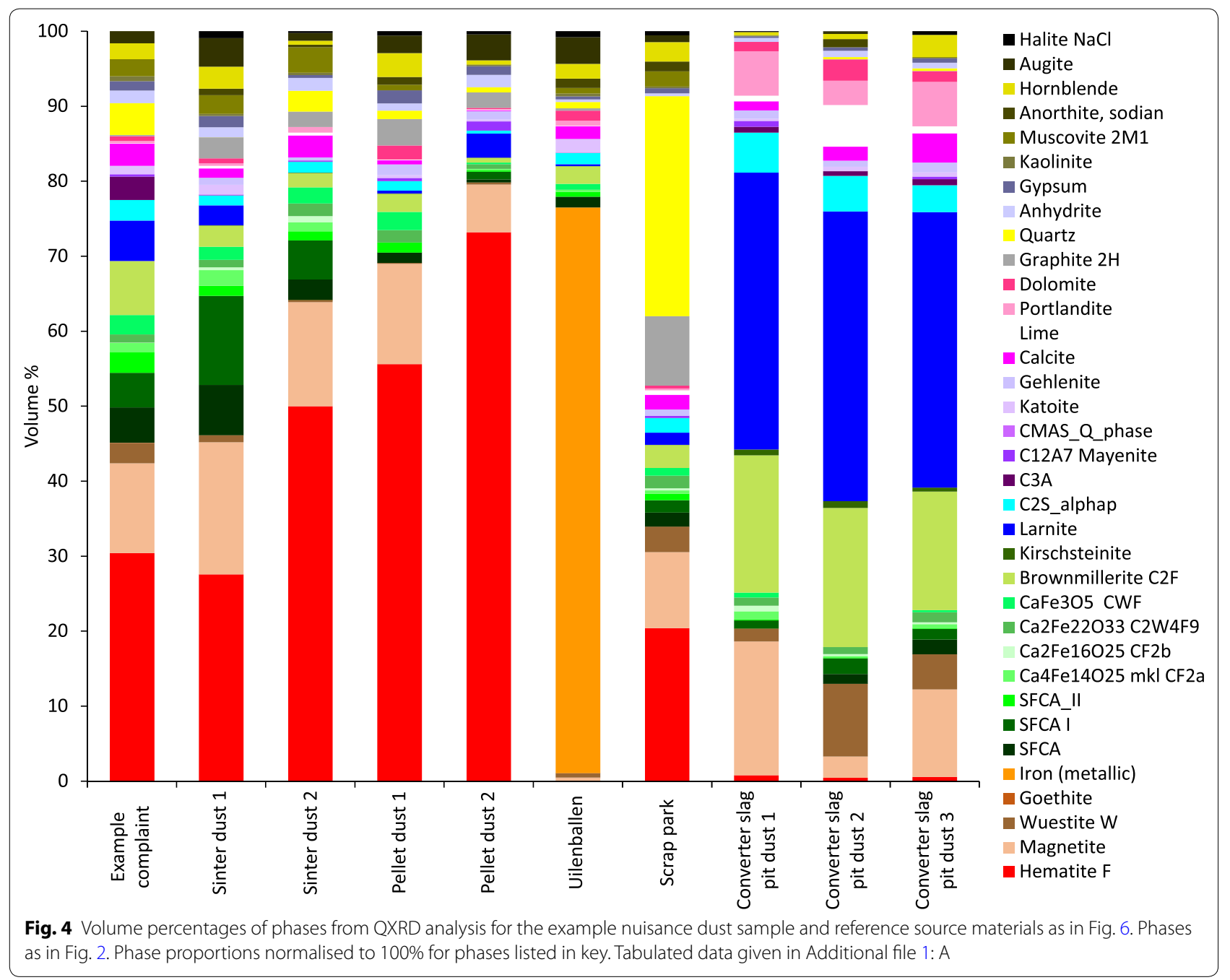

with XRD halite $(\mathrm{NaCl})$; and $\{ \pm, \mathrm{S}, \pm\}$ PARC groups versus gypsum/anhydrite. In all these cases, we interpret the discrepancy as reflecting one or both of the following: (1) PARC analysis detecting material which is amorphous and, hence, not detected by XRD; (2) an over-representation of phases occurring dominantly in thin surface layers on grains in the PARC volumetric estimate, while these are barely detected with XRD due to the deeper penetration of X-rays c. 20-30 $\mu \mathrm{m}$ into the grains' interiors and the small contribution of the surface layers to the bulk grains. The mutual proportions of the Ca-ferrites, ironoxides and quartz are much more closely in agreement between PARC and XRD analyses, suggesting that these phases are fully crystalline and that they are not overrepresented in PARC analyses by occurrence as thin surface layers on grains.

Besides discrepancies due to amorphous material and thin surface layers, the PARC and XRD approaches bring complementary information on the samples. One specific example of this concerns the diverse occurring $\mathrm{Ca}$-ferrites, which in PARC are detected dominantly as the group $\{\mathrm{Ca}, \mathrm{Fe}\}$, while they are readily distinguished with XRD analysis (Table 1, Fig. 4). In iron-ore sinter, the group of Ca-ferrite minerals referred to collectively as silico ferrites of calcium and aluminium (SFCA) is abundant and diagnostic of this material (they do not occur in other industrial source materials). In contrast, the mineral brownmillerite $(\mathrm{C} 2(\mathrm{~A}, \mathrm{~F}))$ is the predominant $\mathrm{Ca}$-ferrite phase in converter-slag reference material. These distinctive mineralogical signatures can be used to refine and independently support estimates of source material contributions to nuisance dust. Overall, the XRD analyses provide independent evaluation of the phases present in a sample and help confirm the detection of source material contributions to nuisance dust samples based on diagnostic phase occurrences. 


\section{Defining grain populations Grain segmentation}

Since the dust characterisation approach is based on individual dust particles, these need first to be recognised and defined, i.e. segmented, as individual objects (grains) in the acquired (spectral-)imagery. Grain segmentation is currently performed on the SEM-BSE image by defining a background grey level to produce a binary mask, followed (where required) by a sequence of pixel-erosion and -dilation steps, and application of a watershed-criterium operation identical to routines in ImageJ [31]. The resultant grain segmentation mask is applied to all correlated images, i.e. SEM-BSE, SI and derived PARC group maps, as well as the quantitative (spectral) information contained therein. The grain segmentation for the exemplary nuisance dust sample is visible in Fig. $1 d$.

\section{General approach to grain classification}

Following grain segmentation (as listed in Fig. 3), data are generated per grain on its size and shape, sub-grains (spatially discrete domains comprising one PARC group), overall chemical composition, constituent PARC group area proportions and their compositions. A (self-developed) decision tree comprising sorting criteria (filters) is then used within PARC to classify individual grains under defined populations (Fig. 5). The filters used in this article are based on the area proportions of certain PARC groups in each grain (including summation, mutual ratios, etc.), which reflect genuine mineralogical phases (and phase intergrowths). The grain size/shape and sub-grain information are not discussed further in this article but can potentially be used to further sub-divide grain populations based on more than solely PARC group abundances (mineralogy). Each filter contains one or more thresholding rules where the result of a given filter is 'true' if and only if all the rules within a given filter are satisfied. Individual grains follow a path through the decision tree filters until they are classified under a population. The decision tree and filters together comprise the grain population model, which is applied consistently to all nuisance dust samples. The model is constructed and refined manually based on a combination of the following approaches:
1) Using characteristic/diagnostic properties of known potential source materials for nuisance dust emission

2) Identifying coherent populations, and their characteristic properties, within nuisance dust samples, which may or may not yet be confidently attributable to specific source materials

Table 2 lists a number of interpretive source materials and distinctive material types identified, referred to henceforth as 'source/material' categories, to which grain populations are assigned (Table 3). Some categories comprise groupings of several grain populations, while others correspond directly with a single grain population. Their key defining mineralogical characteristics are outlined together with the translation of these to PARC group (pixel) abundances as measured in this study. Moreover, independent mineralogical characterisation of a number of potential source materials from XRD analysis (Fig. 4) is used to support the definitions in Table 2. Several key populations can readily be cross-identified by simply inspecting the PARC group maps of both nuisance dust samples and reference samples of potential source materials. Examples include the populations assigned to source/material categories $1-5,7-8$ and 10-13 (Table 2). These are the starting point in defining an initial set of populations, filters and decision tree structure for the grain population model. The grain population model is subsequently expanded and refined in an iterative manner by applying it both to reference samples of potential source materials and nuisance dust samples, assessing the results of the grain classification, modifying the model manually and repeating the cycle. The key aims are to (1) maximise the correspondence between the defined grain populations and specific reference samples where applicable (the evaluation of this is discussed further in the section "Application of grain population model to reference source materials and example nuisance dust sample") and (2) minimise the amount of unclassified grains in nuisance dust samples by defining coherent populations even where no (direct) match is found with any reference source material. The model is regularly updated in response to the results of applying it on new nuisance dust and potential source material samples. Hence, the grain population model shown in this article

(See figure on next page.)

Fig. 5 Flow-chart showing full decision tree structure of grain population model for classifying grains. Numbered diamonds represent filters (filter contents are tabulated in Additional file 1: B). Coloured rectangles represent grain populations described in Table 3. Arrows indicate flow direction of connectors between nodes. Key shows assignment of populations to interpretive source/material categories listed in Table 2. Note, alphabetic labelling of populations reflects order in which these appear in decision tree and hence deviates from order in key 


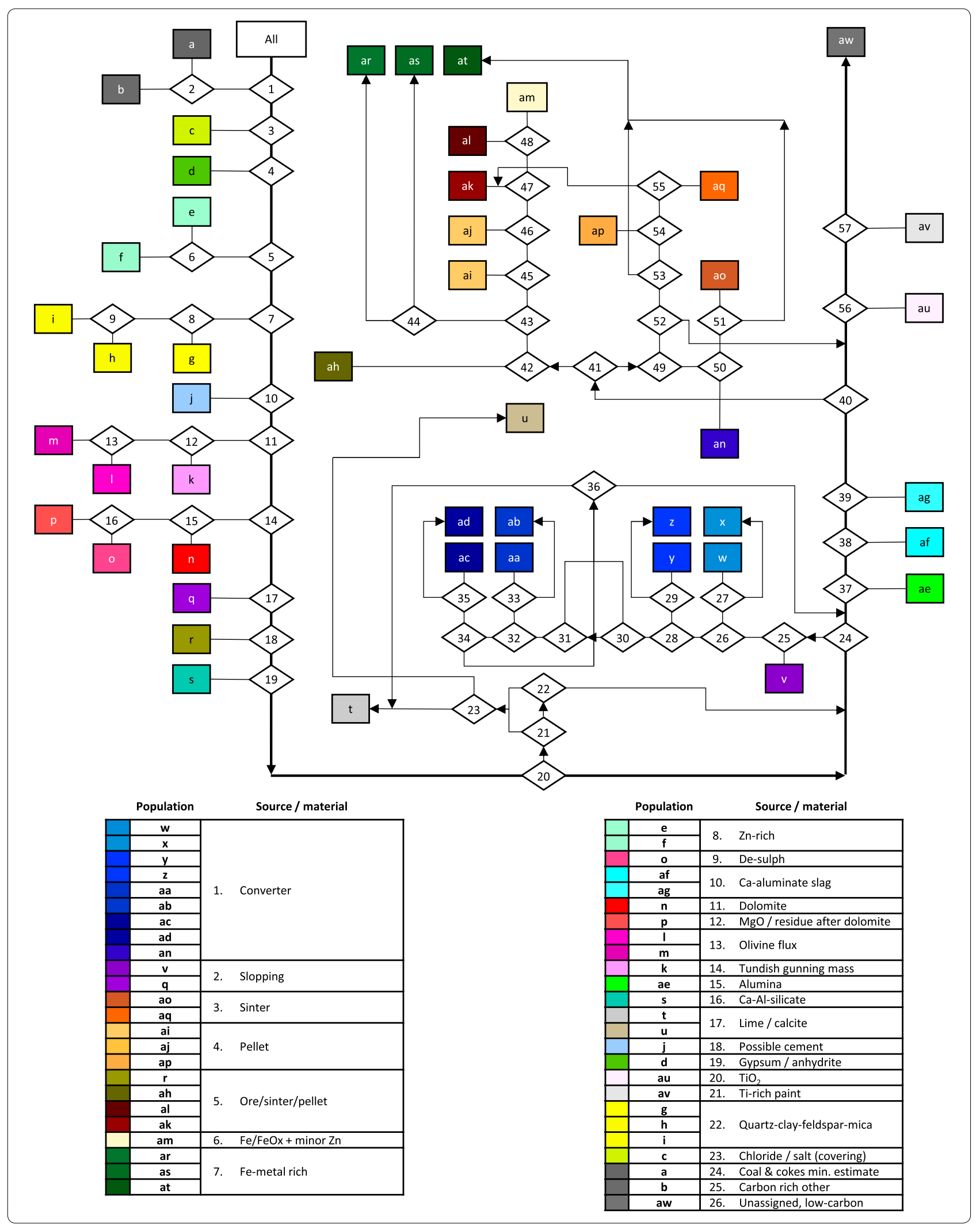




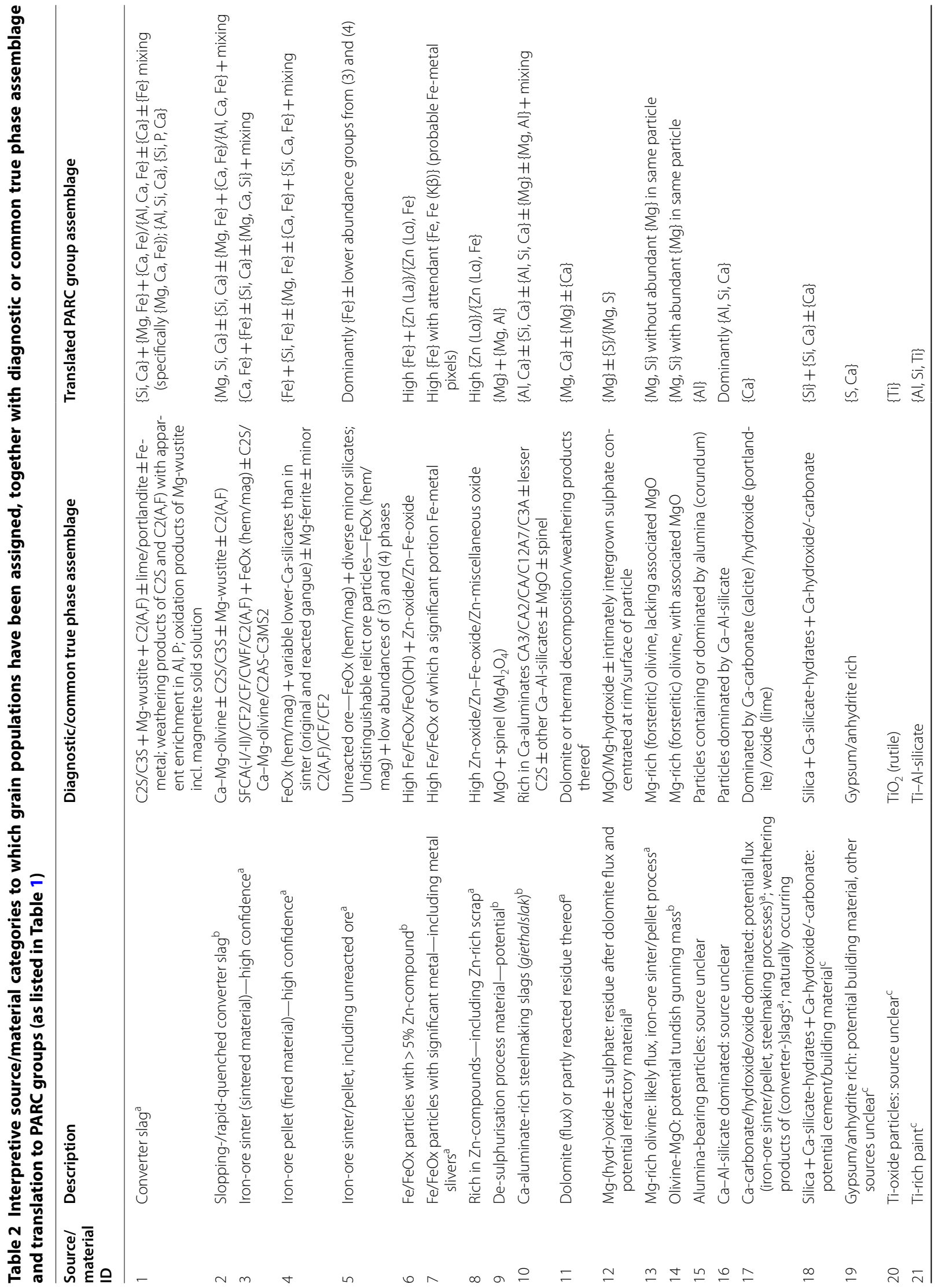




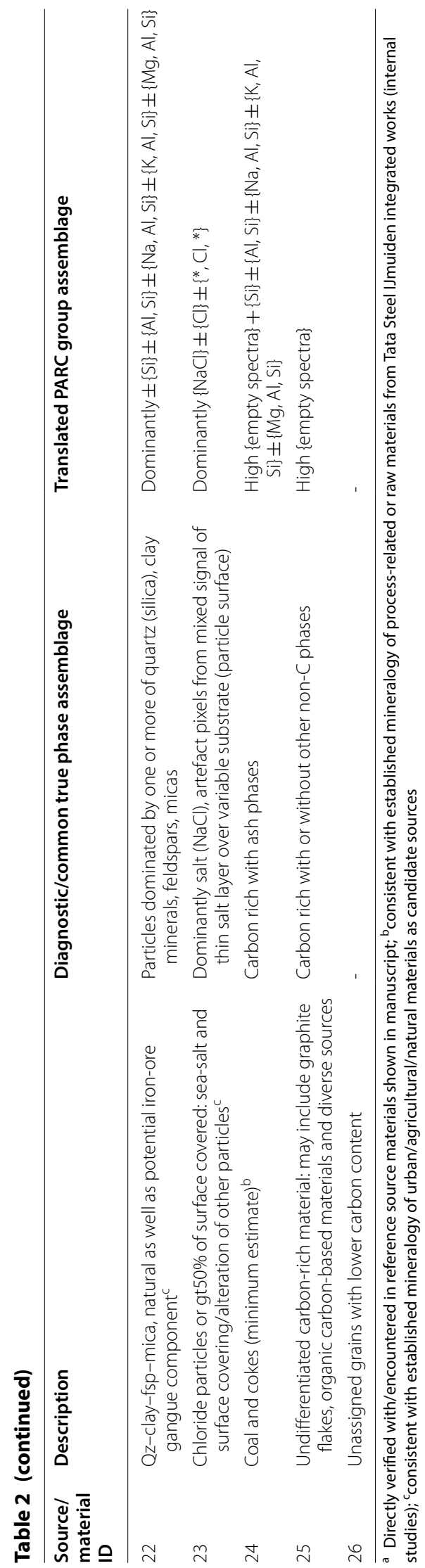




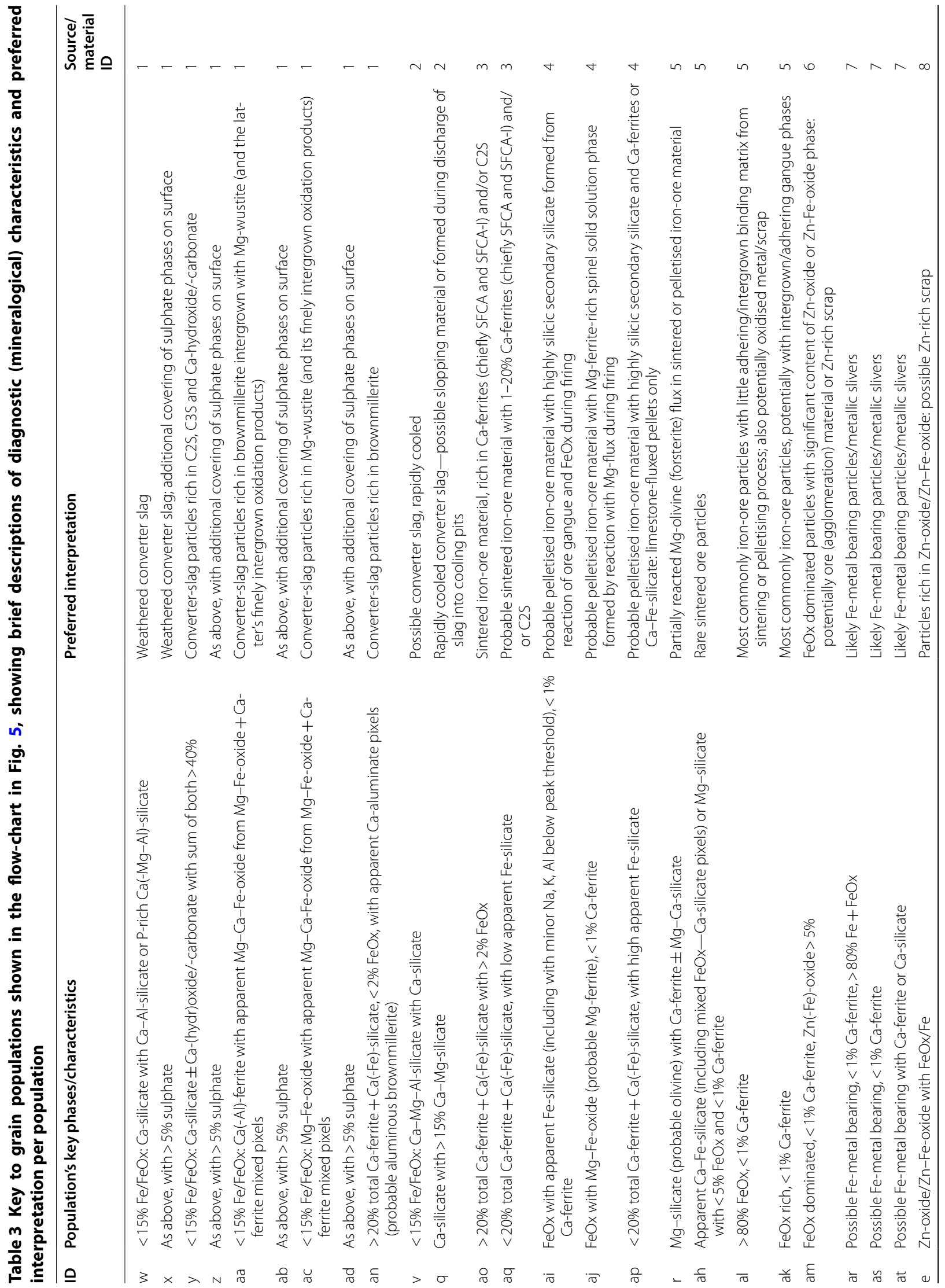




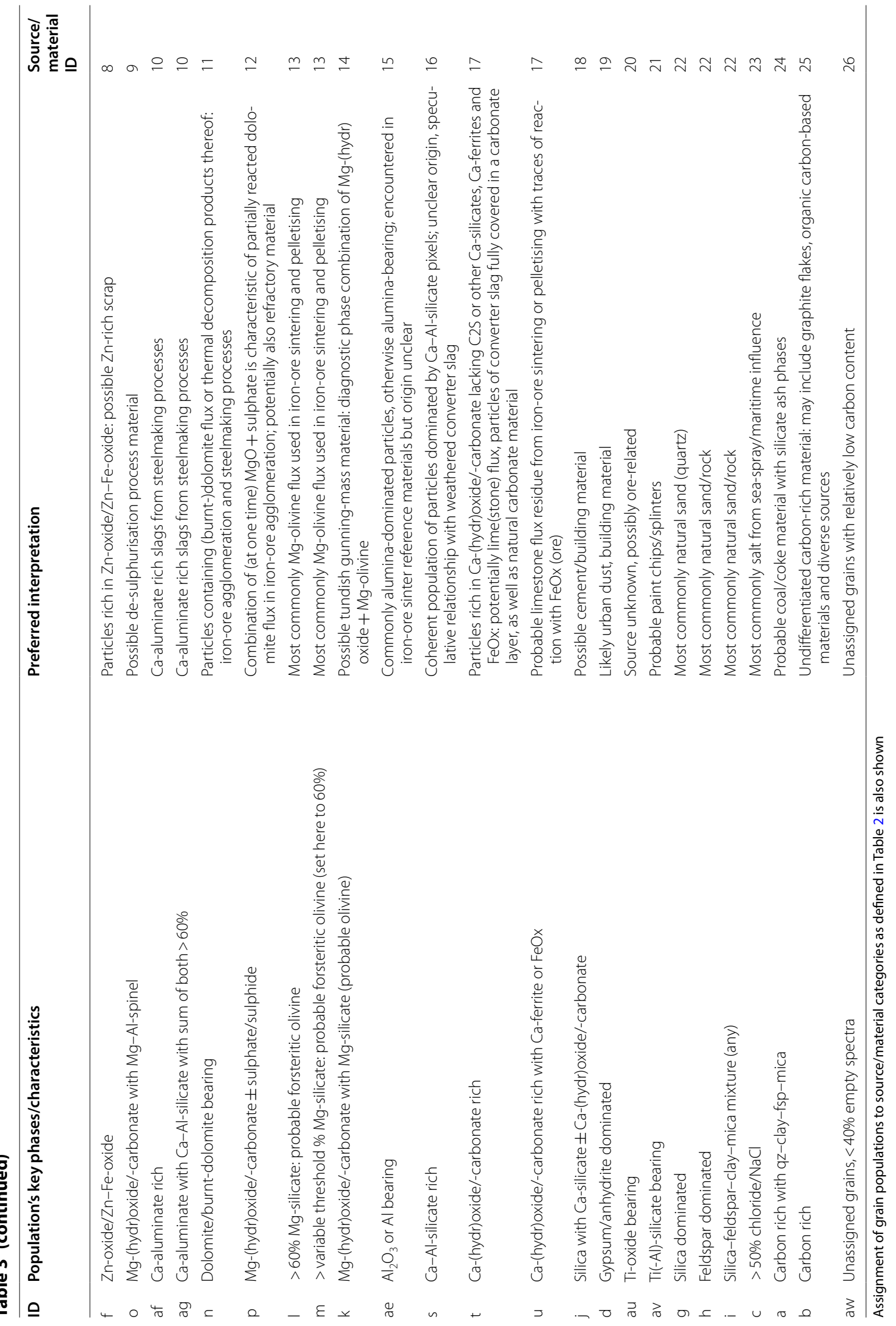


is necessarily a snapshot of its state of development at time of writing.

The main advantages of a manual decision tree approach are related to the transparent, 'white box' nature of the model, which allows full insight into how particles are classified. Disadvantages of this approach include the possibility of overlooking genuine but less-strikingly obvious populations while also potentially generating artefact populations by defining them too broadly or too tightly. The PARC data output lends itself readily to deeper statistical analysis and further work is in progress on interrogating the data, including on strengthening grain population classification and correspondence with source materials.

\section{Reference source materials}

Ultimately, the grain population classification approach requires validation on well-defined reference materials where the provenance of the material is independently known. Several reference samples are discussed in this article:

- Dusts from conveyor belts transporting iron-ore sinter (sinter dust 1) and iron-ore pellet (pellet dust 1) material from their respective production sites to the charging point of the blast furnace;

- Dusts sampled at the sintering plant (cooling section; sinter dust 2) and pelletising plant (abrasion-testing facility; pellet dust 2);

- Metal-rich slivers from a scrap processing facility (uilenballen);

- Dust from a scrap park location (scrap park);

- Three dust samples (sieved to $<125 \mu \mathrm{m}$ ) taken from the pits used to discharge and cool converter slag prior to further processing (converter-slag pit dusts $1-3)$.

The setup and refinement of the grain population model were based to a large extent on using one of each type of the reference materials listed above, while in the case of the sinter, pellet and converter-slag reference materials, additional similar samples of each were treated purely as unknown materials for validation purposes (samples 2 and 3 of each material type in the list, where applicable). Figure 4 shows the volume percentages of phases from XRD analysis for the above reference materials, alongside the example nuisance dust sample (full tabulated data and indexed diffraction patterns are given in Additional file 1: A). The reference samples pertaining to sinter-, pellet- and converter-slag pit dust are clearly distinguished by their bulk mineralogical compositions. These mineralogical characteristics are taken directly into account in Table 2 for defining the diagnostic/ common true phase assemblage for source/material categories (1) converter slag, (3) iron-ore sinter (sintered material) and (4) iron-ore pellet (fired material). The results of applying the grain population model to the above listed reference materials are shown in the section "Application of grain population model to reference source materials and example nuisance dust sample".

\section{Grain population model}

Figure 5 shows the full decision tree structure for the developed grain population model applied here. Table 3 lists the 49 grain populations shown in the flow-chart and provides brief text descriptions of the defining characteristics of each population, the preferred interpretation of each population and assignment to the 26 source/ material categories described in Table 2 (including that of unassigned grains). Complete filter definitions for Fig. 5 are tabulated in Additional file 1: B.

\section{Quantification of volumetric contributions}

Ultimately, the volumetric and mass contributions of nuisance dust particles are of interest, while additionally the sizing and (specific) surface area of particles are highly relevant for understanding environmental behaviour and bio-availability of toxic species. The nuisance dust particles (grains) have very variable shapes and tend to rest on their largest cross-section in the mounted sample. Translating the directly measured silhouette area fraction (reported in the figures and tables here) to volume fraction without any further stereographic correction implicitly assumes perfectly plate-shaped particles of equal thickness (rising above the sample mount). This is clearly not a realistic assumption for more spherical particles, while even genuinely platy-shaped particles have a wide range of aspect ratios and are not guaranteed to be oriented resting on their largest flat face. This is currently the main source of error in estimating volumetric contributions of grains and grain populations to the bulk samples. Our expectation is that (ongoing) further quantitative exploitation of 3D microscopic imagery will substantially improve estimates of volumetric and surface area contribution from different particle populations. The combination of QXRD and PARC analyses, meanwhile, provides an important internal consistency check regarding the volumetric proportions of mineralogical phases and can help flag up the occurrence of some phases disproportionately concentrated in thin superficial layers on particles. 


\section{Results and discussion: application of grain population model and quantitative information extracted}

Source apportionment of grain populations

Broadly speaking, the grain populations can be split between IJmuiden steelworks-derived, urban and natu$\mathrm{ral} /$ agricultural contributions in the dust. The source/ material categories listed in Table 2 most unequivocally attributable to the steelworks are 1-6 and 9-14, since for these, there are no plausible alternative sources to steelmaking raw materials (ores, fluxes), intermediate products (iron-ore agglomerates), by-products (slags) and highly specific installation materials (refractory materials). Source/material categories 6-8, 15 and 16 are found in samples collected on-site but are not yet uniquely attributed to a specific process or raw material. Ca-carbonate (most commonly calcite) is a natural rock-forming mineral which can occur as seashells in the local natural environment, while as limestone it is a raw material (flux) for steelmaking processes. It can also form as a weathering product of converter (and other calcic) slag. As such category 17 (Ca-carbonate/ (hydr)oxide) is a potentially ambiguous category of dust particles, except in cases where steelmaking-diagnostic phases are observed in conjunction with these particles. Currently, the carbon-rich grain populations are not optimally sub-divided and source/material category 24 may include coal, cokes, graphite and peat and pollen (natural). Urban dust sources include various building materials, glass, and paints: cement (category 18) and paint (category 21, potentially category 20) are identified as potential source materials for grain populations in the presented model based on widely known characteristics of these materials [32, 33]. Gypsum (category 19) can be both urban building material and directly steelmaking process/site related. Natural dust sources include sand, rich in quartz with lesser quantities of feldspar, and weathering products such as claywhich are currently grouped together under the source/ material category 22. The surface contaminant $\mathrm{NaCl}$ is traceable to sea spray and has been observed partially covering the surface of diverse particles.

\section{Application of grain population model to reference source materials and example nuisance dust sample}

Following classification of grains to populations, data are generated per grain population as specified in Fig. 3. Here, we focus on the relative abundances of grain populations, their mineralogical makeup and (micro-)chemical attributes, which are of relevance for further understanding their provenance as well as the distribution of specific (potentially toxic) chemical elements on the population and phase level.

Table 4 reports the area proportions of all defined grain populations for the example nuisance dust sample of Fig. 1 and for the reference source material samples referred to earlier in this section. The area proportions of the interpretive source/material categories, to which the populations are assigned, are shown in Fig. 6 (tabulated in Additional file 1: C; original SEM-BSE and PARCgenerated images are given in Additional file 1: D, along with tabulated area percentages of all PARC groups per sample). This set of results gives an important indication of the performance of the grain population model in distinguishing three key potential source materials-converter slag, iron-ore sinter and pellets-for which their respective particle (grain) populations are expected to have overlapping apparent mineralogy in terms of PARC group abundances. It can be seen that there is a very good correspondence between the defined grain populations and their respective interpretive source materials, with minimal overlap of $1 \%$ or less between the converter-slag and sinter dust samples and $<5 \%$ overlap between sinter and pellet dust samples, where overlap refers to misallocation regarding source such as 'pellet' grains in a sinter reference dust or vice versa. Similarly, the discrimination between particles rich in $\mathrm{FeOx}$, prevalent in ironore sinter and pellets, and Fe-metal-rich particles such as encountered in the uilenballen sample, is also strong. Only around $2 \%$ or less (by area) of the pellet dust is classified as potentially metal rich (source/material 7), while in the uilenballen sample $>90 \%$ is classified this way. The remainder of the uilenballen grains are dominantly classified as source/material 5, with around $7 \%$ area contribution, though they are upon detailed inspection not considered to be ore/sinter/pellet related. Hence, there is in this grain population clearly some potential overlap in the classification of grains that are rich in $\mathrm{FeOx}$ from different sources. The scrap-park sample contains a significant population of grains (source/material 8) rich in $\mathrm{Zn}$-oxide/Zn-Fe-oxide, while a small amount (c. $1 \%$ area) of clearly similar grains is also found in converter-slag pit dust sample 2. The scrap-park sample is a case in point of the challenges in finding appropriate reference samples for source materials: while the sampling location is clearly defined, the material collected there is highly heterogeneous, as can be seen in the lack of any single dominant grain population or source/material category. Detailed examination of this sample confirms that the grains classified as ore/sinter/pellet (5), pellet (4), sinter (3), converter (1) strongly resemble their counterpart populations in their respective reference source materials, while a significant portion of the material appears to be natural silicates (22: quartz-clay-feldspar-mica). The 


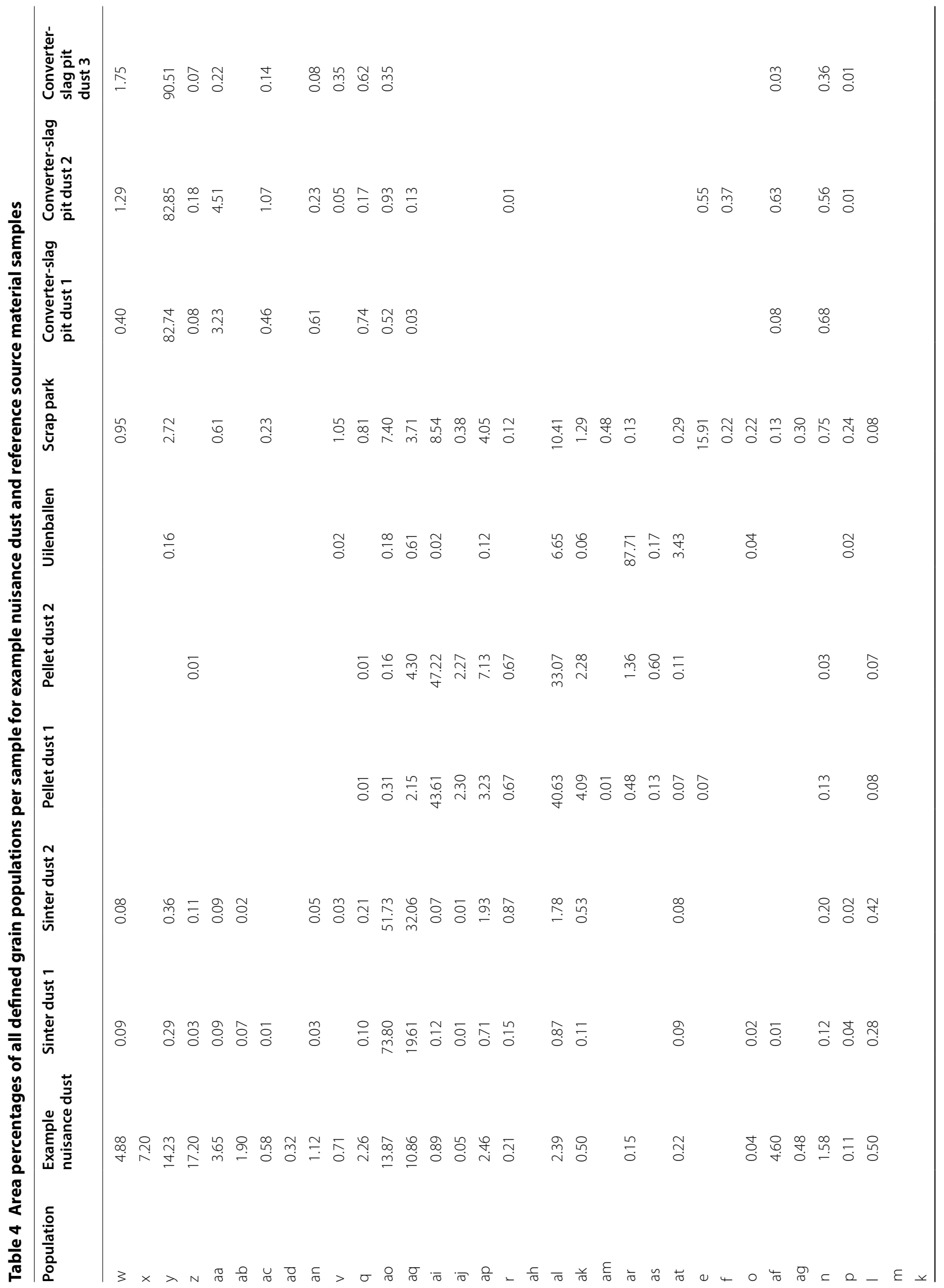




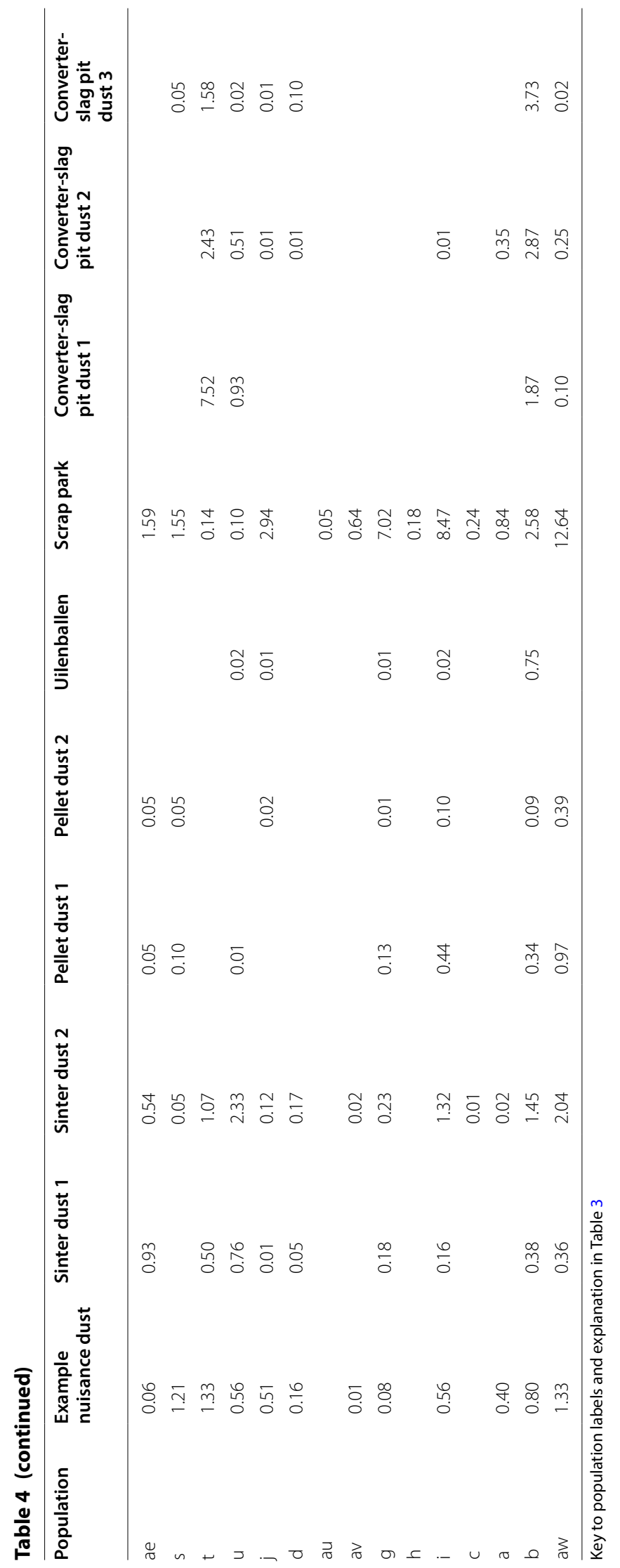




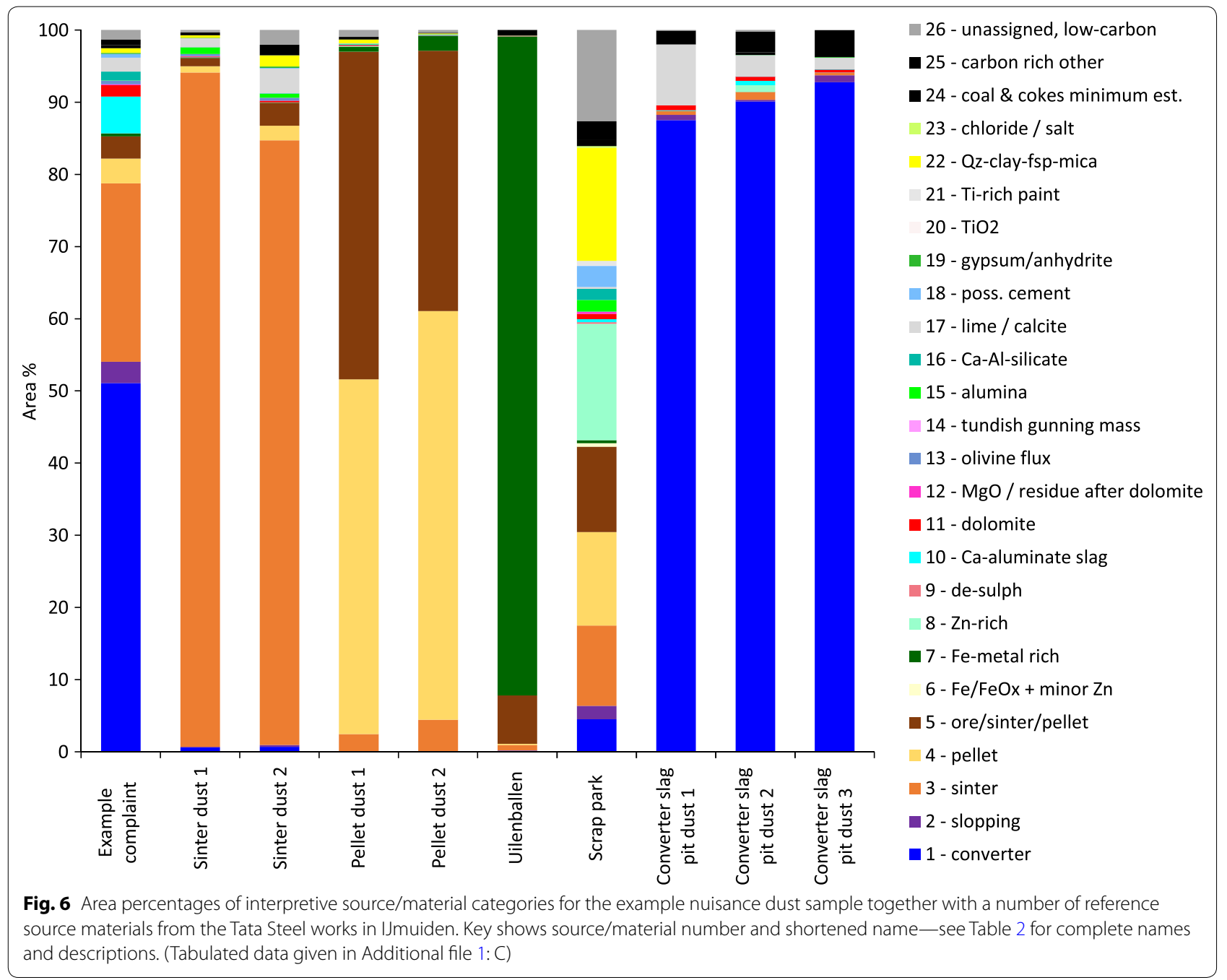

relatively large area fraction of unassigned grains contains numerous diverse silicate phases also considered likely to be of natural origin in most cases. The only grain populations considered likely to be associated with scrap material are those falling under source/material category 8 ( $\mathrm{Zn}$ rich). The interpretation is that this sampling location captured a heterogeneous population of dust particles of which only small portion is derived from the material hoped to be sampled there.

Another key source material is not verified directly with regard to a reference sample here-(10) Ca-aluminate slag-since this source material is mineralogically distinctive and indicative of a well-defined set of steelmaking process slags which are mixed and processed together at their suspected emission point.

\section{Mineralogy of example nuisance dust sample}

Applying this grain population model, about $90 \%$ of the analysed area of the nuisance dust sample is found to be composed of source/material categories 1 (converter), 2 (slopping slag), 3 (sinter), 4 (pellet), 5 (ore/sinter/pellet) and 10 (Ca-aluminate slag); while converter- and sinterrelated populations are clearly the two dominant contributors (Fig. 6). Figure 7 provides a graphical summary of the mineralogical makeup of the bulk sample and the diversity of its constituent grain populations with $>0.5 \%$ area contribution (full data are tabulated in Additional file 1: E).

Clearly, the PARC group proportions chiefly reflect the filters used to classify the grains under their respective populations. Nevertheless, the distinctive characteristics of a grain population regarding its constituent PARC groups help to understand its provenance and its potential health implications in terms of distribution of hazardous elements in the constituent mineral phases. A few points merit some discussion here.

The converter-slag populations (source/material category 1) vary widely in their PARC group abundances in 


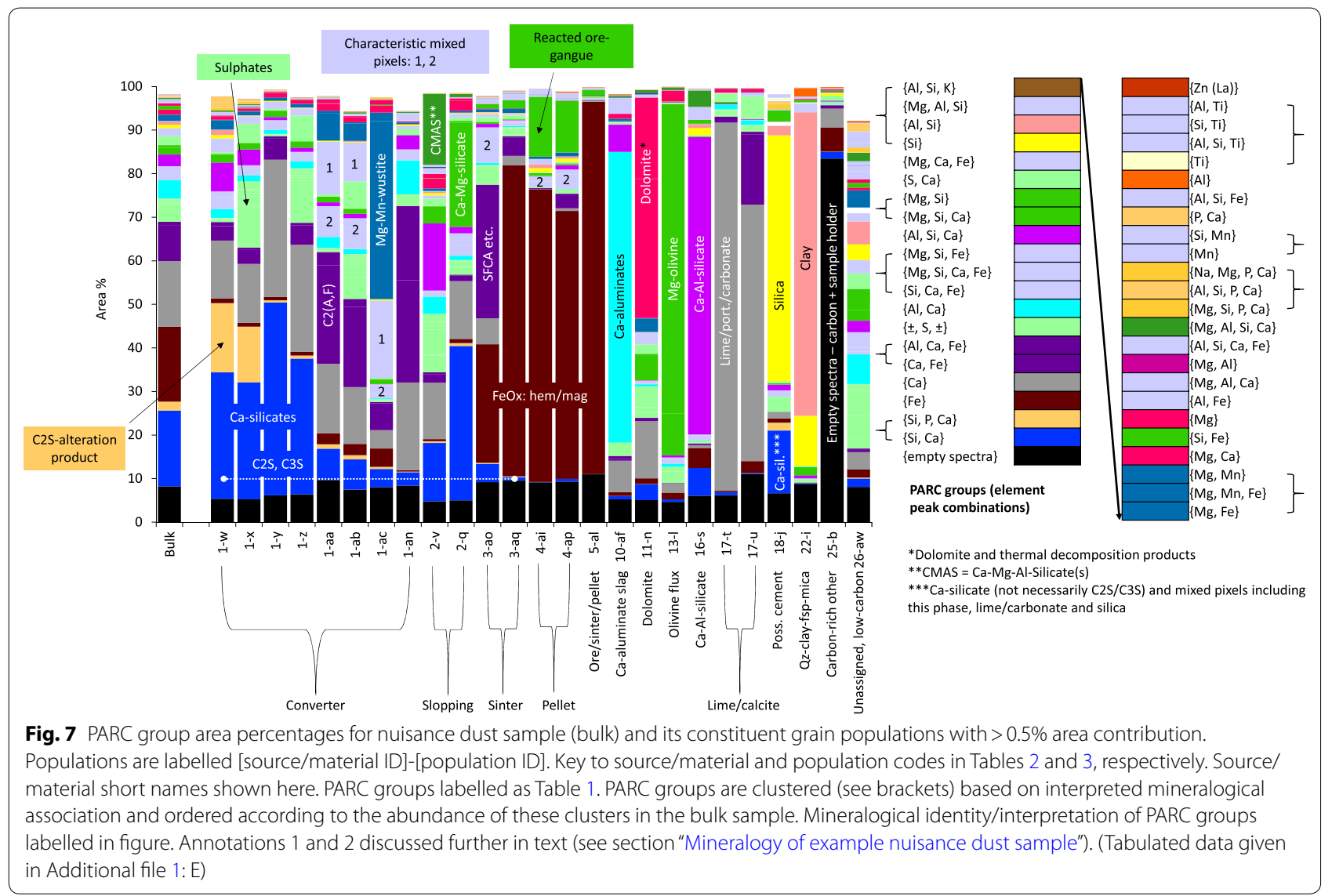

line with the series of filters used in each case. Essentially, the populations are split into three types of relatively 'pristine' converter-slag particles based on the predominance of each of the three major converter-slag phases C2S (or C3S; populations y and z), C2(A,F) (populations aa and $\mathrm{ab}$ ) and Mg-wustite (populations ac and ad); plus 'weathered' converter-slag material ( $\mathrm{w}$ and $\mathrm{x}$ ) characterised by the presence of distinctive $\mathrm{P}$ - and Al-enriched (hydrated/carbonated) silicate phases formed by alteration of the original slag phases. These populations are further sub-divided based on the presence/absence of significant abundance of sulphate phases on-at leastthe surface of the grains, which is clearly seen in the PARC group proportions in the figure. Compared with the reference dust materials sampled in the converterslag cooling pits, the converter-attributed grains in the nuisance dust sample are markedly different in their detailed breakdown into populations and their mineralogy. Closely inspecting Table 4 reveals that the grains in the reference converter-slag pit dust samples are overwhelmingly classified as population y, i.e. pristine C2S/ C3S-dominated grains with no significant covering of sulphate, followed by minor $(<5 \%)$ population aa $(\mathrm{C} 2(\mathrm{~A}, \mathrm{~F})$ rich grains) and a small but clearly verified abundance (upon detailed inspection) of the 'weathered' slag population $\mathrm{w}$. The example nuisance dust sample contains much more weathered slag population ( $\mathrm{w}$ and $\mathrm{x}$ ) as a fraction of the total converter-attributed grains and, moreover, a large portion of all the different converter-attributed grains have a significant covering of sulphate group pixels. While these weathered- and sulphate-covered grain populations are scarce in the reference converter-slag pit dust samples, they are still clearly recognisable there as being equivalent to the grains encountered in the nuisance dust. The preferred interpretation is that the converter-attributed material in the nuisance dust sample is, on the whole, significantly more weathered as well as having more sulphate covering it than the relatively pristine material encountered in the three reference dust samples from the cooling pits. Such detailed, nuanced information is being used to glean a better understanding of the formation mechanisms of the dust from converter slag and its further propagation into the surroundings.

Annotations 1 and 2 in Fig. 7 highlight the abundances of specific PARC group pixels chiefly associated with mixing of two or more true phases where these are finely intergrown with one another. The converter-slag populations contain abundant $\{\mathrm{Mg}, \mathrm{Ca}, \mathrm{Fe}\}$ 
Table 5 Quantitative chemical analysis from EDS sum-spectra per bulk grain population for populations with $>0.5$ area $\%$ contribution, reported as oxide (or element) wt $\%$ and normalised to $100 \%$ of the elements above detection limit (values > 3-sigma error in quantification result)

\begin{tabular}{|c|c|c|c|c|c|c|c|c|c|c|c|c|c|c|c|c|}
\hline Source /mat & Pop & Area \% pop & $\mathrm{Na}_{2} \mathrm{O}$ & $\mathrm{MgO}$ & $\mathrm{Al}_{2} \mathrm{O}_{3}$ & $\mathrm{SiO}_{2}$ & $\mathrm{P}_{2} \mathrm{O}_{5}$ & $\mathrm{SO}_{3}$ & $\mathrm{Cl}$ & $\mathrm{K}_{2} \mathrm{O}$ & $\mathrm{CaO}$ & $\mathrm{TiO}_{2}$ & $\mathrm{~V}_{2} \mathrm{O}_{5}$ & $\mathrm{MnO}$ & $\mathrm{FeO}$ & $\mathrm{ZnO}$ \\
\hline 1 & w & 4.88 & 1.0 & 4.4 & 4.1 & 13 & 4.3 & 2.4 & 0.5 & 0.1 & 39 & 2.4 & 1.1 & 4.3 & 24 & - \\
\hline 1 & $x$ & 7.20 & 0.9 & 3.0 & 3.5 & 14 & 4.0 & 6.7 & 0.6 & 0.1 & 42 & 2.2 & 0.9 & 3.0 & 19 & - \\
\hline 1 & $y$ & 14.23 & 0.5 & 2.4 & 2.2 & 13 & 1.6 & 2.0 & 0.2 & - & 50 & 1.9 & 0.9 & 3.3 & 23 & 0.1 \\
\hline 1 & z & 17.20 & 0.7 & 2.6 & 2.5 & 12 & 1.6 & 6.3 & 0.3 & 0.1 & 46 & 1.8 & 0.8 & 3.3 & 22 & 0.1 \\
\hline 1 & aа & 3.65 & 0.4 & 6.1 & 2.4 & 5.7 & 1.1 & 1.9 & 0.2 & - & 29 & 1.7 & 0.8 & 7.5 & 43 & 0.1 \\
\hline 1 & $a b$ & 1.90 & 0.7 & 4.7 & 2.8 & 6.5 & 1.3 & 6.0 & 0.3 & - & 28 & 1.6 & 0.7 & 6.2 & 41 & 0.1 \\
\hline 1 & $\mathrm{ac}$ & 0.58 & 0.1 & 21 & 1.3 & 3.2 & 0.5 & 1.0 & 0.1 & - & 13 & 0.9 & 0.5 & 13.5 & 45 & - \\
\hline 1 & an & 1.12 & 0.4 & 1.5 & 7.4 & 4.6 & 0.4 & 2.5 & 0.4 & 0.2 & 39 & 3.3 & 1.2 & 2.4 & 37 & - \\
\hline 2 & v & 0.71 & 0.8 & 8.2 & 8.6 & 14 & 1.0 & 4.0 & 0.4 & 0.1 & 42 & 1.5 & 0.4 & 2.3 & 16 & - \\
\hline 2 & $q$ & 2.26 & 0.5 & 6.4 & 2.4 & 16 & 1.7 & 2.4 & 0.3 & 0.1 & 41 & 1.9 & 1.0 & 5.6 & 21 & - \\
\hline 3 & ao & 13.87 & 0.6 & 1.6 & 2.4 & 5.3 & 0.4 & 2.7 & 0.2 & 0.1 & 17 & 0.6 & 0.2 & 2.6 & 66 & 0.2 \\
\hline 3 & $\mathrm{aq}$ & 10.86 & 0.5 & 1.1 & 2.1 & 2.7 & 0.3 & 1.5 & 0.1 & 0.1 & 5.5 & 0.4 & 0.1 & 0.7 & 85 & - \\
\hline 4 & ai & 0.89 & 0.7 & 2.1 & 3.0 & 7.1 & 0.2 & 0.6 & - & 0.4 & 2.8 & 0.2 & 0.1 & 0.3 & 83 & - \\
\hline 4 & ap & 2.46 & 0.6 & 1.7 & 3.1 & 6.1 & 0.1 & 1.0 & - & 0.1 & 4.5 & 0.3 & 0.1 & 0.6 & 82 & - \\
\hline 5 & al & 2.39 & 0.3 & 0.9 & 1.0 & 1.9 & 0.1 & 0.6 & - & - & 2.5 & 0.1 & 0.1 & 0.4 & 92 & - \\
\hline 10 & af & 4.60 & 0.3 & 3.7 & 31 & 3.7 & 0.6 & 2.7 & 0.2 & - & 47 & 1.1 & - & 2.3 & 7.7 & - \\
\hline 11 & $n$ & 1.58 & 0.4 & 33 & 2.4 & 5.5 & 0.5 & 5.3 & 0.3 & - & 35 & 0.6 & 0.6 & 3.5 & 13 & - \\
\hline 13 & 1 & 0.50 & - & 42 & 1.0 & 32 & - & 0.4 & - & 0.2 & 5.5 & 0.3 & 0.2 & 0.7 & 19 & - \\
\hline 16 & s & 1.21 & 1.2 & 2.7 & 14 & 38 & 0.6 & 1.1 & 0.1 & 0.9 & 19 & 1.1 & 0.0 & 0.4 & 21 & - \\
\hline 17 & $t$ & 1.33 & 0.4 & 1.6 & 1.8 & 2.7 & 0.5 & 3.2 & 0.3 & 0.1 & 66 & 1.3 & 0.4 & 3.2 & 18 & - \\
\hline 17 & u & 0.56 & 0.4 & 1.5 & 1.9 & 2.8 & 0.4 & 5.1 & 0.4 & 0.2 & 49 & 0.6 & 0.4 & 2.4 & 35 & - \\
\hline 18 & j & 0.51 & 0.5 & 0.5 & 0.9 & 74 & 0.5 & 3.0 & 0.2 & - & 8.0 & 0.7 & 0.1 & 0.4 & 12 & - \\
\hline 22 & i & 0.56 & 0.5 & 3.8 & 26 & 53 & 0.8 & 2.8 & 0.2 & 0.7 & 4.4 & 1.0 & - & 0.5 & 7.2 & - \\
\hline 26 & aw & 1.33 & 1.6 & 10 & 10 & 21 & 2.3 & 3.5 & 0.1 & 0.7 & 19 & 1.1 & 0.2 & 6.4 & 23 & 0.9 \\
\hline
\end{tabular}

Elements are reported with assumed oxide forms (except $\mathrm{Cl}$ ). See Tables 3 and 2 for key to, respectively, populations and source/material

pixels (annotation 1), which is a characteristic feature of converter-slag reference materials and has been used to strengthen the filters to discriminate between converter- and sinter-related grains (hence, the results here strongly reflect that filtering). These are interpreted as mixed pixels reflecting finely intergrown $\mathrm{Mg}$-wustite $\{\mathrm{Mg}, \mathrm{Fe}\}$ and $\mathrm{C} 2(\mathrm{~A}, \mathrm{~F})\{\mathrm{Ca}, \mathrm{Fe}\}$. Both converter-slag and iron-ore sinter/pellet populations contain an abundance of $\{ \pm \mathrm{Mg}, \pm \mathrm{Ca}, \mathrm{Fe}, \mathrm{Si}\}$ pixels (annotation 2), which reflect different fine phase intergrowths in each case. For the converter-slag grain populations, these pixels represent intergrowth of $\mathrm{C} 2 \mathrm{~S} / \mathrm{C} 3 \mathrm{~S}\{\mathrm{Si}, \mathrm{Ca}\}$ with $\mathrm{Mg}$-wustite $\{\mathrm{Mg}, \mathrm{Fe}\}$. For the sinter/pellet grain populations, they represent mixed pixels of variously $\mathrm{C} 2 \mathrm{~S}$, silicate glass, $\mathrm{Mg}$-ferrite, $\mathrm{Mg}(-\mathrm{Ca})$-olivine and diverse $\mathrm{Ca}-\mathrm{Mg}-\mathrm{Fe}$-silicates, which occur abundantly in sintered or pelletised material but not in unreacted ore material. Population al (labelled 5-al in Fig. 7) is notably lacking in these pixels, consistent with it being largely unreacted ore material.

\section{Quantified chemistry of grain populations}

Quantitative chemical analyses per grain population have been derived for the example nuisance dust sample by processing their respective EDS sum-spectra (as described in the section "SEM and EDS spectral imaging"). The results are shown in Table 5 and Fig. 8 for grain populations contributing $0.5 \%$ or more (shown by the superimposed line in the figure). These chemical analyses are broadly in line with expectations for the respective source/material categories. The converter-related populations (source/material 1) vary rather widely, which in the case of populations y and $\mathrm{z}$ (C2S/C3S rich), aa-ab $(\mathrm{C} 2(\mathrm{~A}, \mathrm{~F})$ rich) and ac (Mg-wustite rich) chiefly reflects the relative abundance of the three main converter-slag phases. The 'weathered' converter-slag populations $\mathrm{w}$ and $\mathrm{x}$ resemble the $\mathrm{C} 2 \mathrm{~S} / \mathrm{C} 3 \mathrm{~S}$-rich populations $\mathrm{y}$ and $\mathrm{z}$, while deviating in the $\mathrm{Al}$ and $\mathrm{P}$ concentrations-reflecting the abundance of the interpreted weathering product phases represented by the PARC groups $\{\mathrm{Al}, \mathrm{Si}, \mathrm{Ca}\}$ and $\{\mathrm{Si}, \mathrm{P}, \mathrm{Ca}\}$, respectively. The sulphur concentration of the converter-related populations varies strongly according 


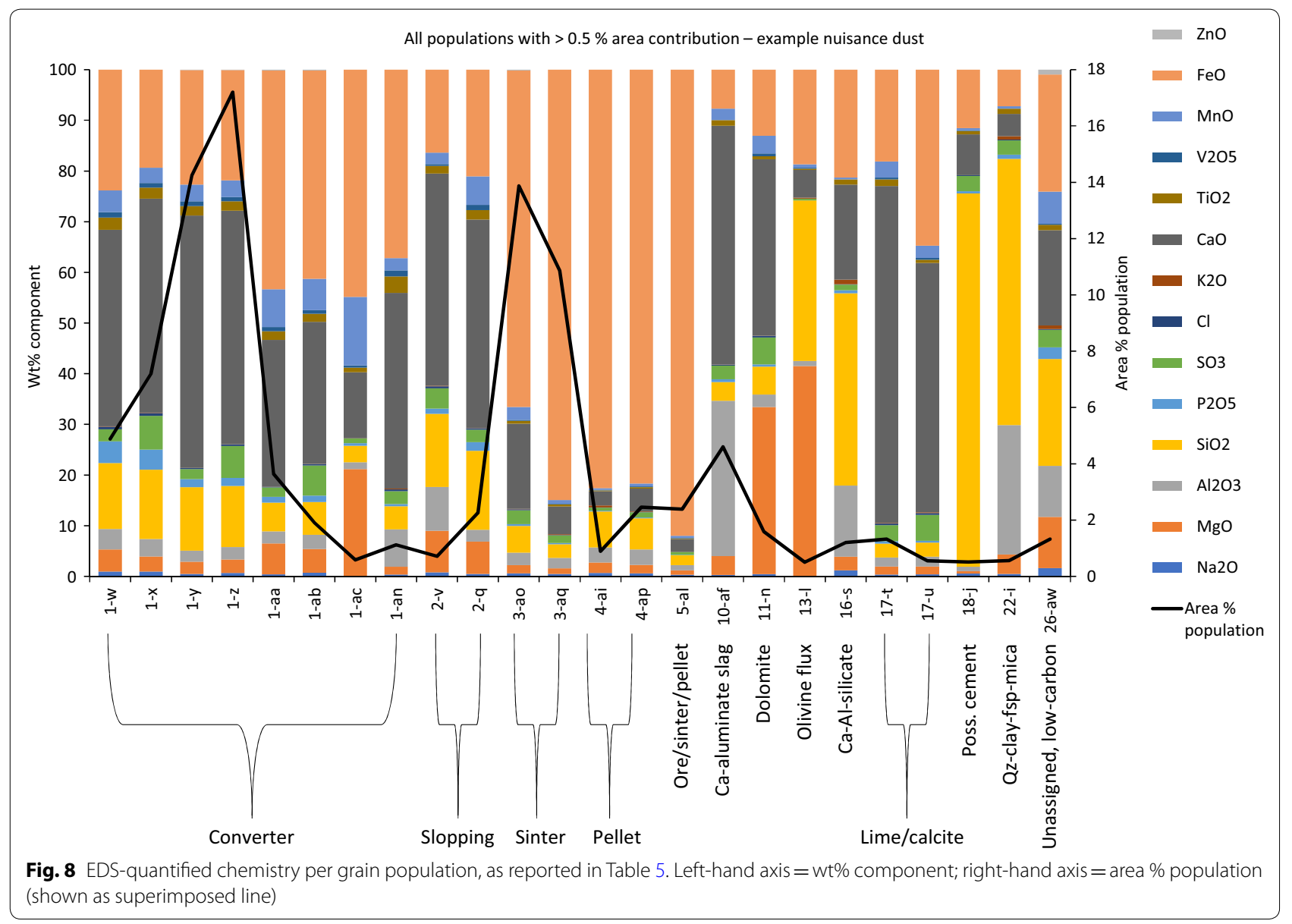

to whether the population was defined as being 'sulphate rich' or not. Clearly, the bulk chemistry of the grains comprising the various converter-related populations varies very widely, corresponding with large variations in the mineralogy of individual grains. This illustrates the difficulty of classifying grains based only on their bulk chemical composition, versus the ability to draw together chemically disparate grains based on their related mineralogy. A key additional reason for basing grain classification on mineralogical phase proportions (via PARC groups) is the commonly heavy contamination and alteration of the surface by/to other phases. This may lead to significant deviations in chemistry between the analysed surface and the true bulk chemistry of the grains. By classifying grains based on characteristic proportions of specific PARC groups, it is possible to screen out likely surface contaminant and alteration products. These are classified as distinct PARC groups and can be excluded from the expressions in the filters. Based only on bulk chemistry per grain, such surface artefacts are much more difficult to screen out.

\section{Mode of occurrence of identified potentially toxic elements- $\mathrm{V}, \mathrm{Mn}$}

In a recent study [34] by the Dutch National Institute for Public Health and the Environment (RIVM) on dust deposits in the town Wijk aan Zee, three elements V, $\mathrm{Mn}$ and $\mathrm{Pb}$ were detected with potential exposure health risk. Their occurrence was not coupled to any specific source of dust other than that implied by the vicinity to the steel production facility. To estimate the health risk of dust particles, the dosimetry of its constituent elements needs to be determined [9]. For the chemical analysis as performed by the RIVM study, aqua regia digestion will likely dissolve most material, with the exception of quartz and other relatively insoluble minerals. The elemental composition analysed in this way can serve to determine a maximum health risk in the scenario that all elements were to become available in solution [34]. In the case of human ingestion of dust, dissolution of coarse particles may occur to a lesser extent during passage through the digestive tract than during the aqua regia preparation used for analysis. For those phases hosting V, Mn and $\mathrm{Pb}$, knowing their solubility and dissolution kinetics in 


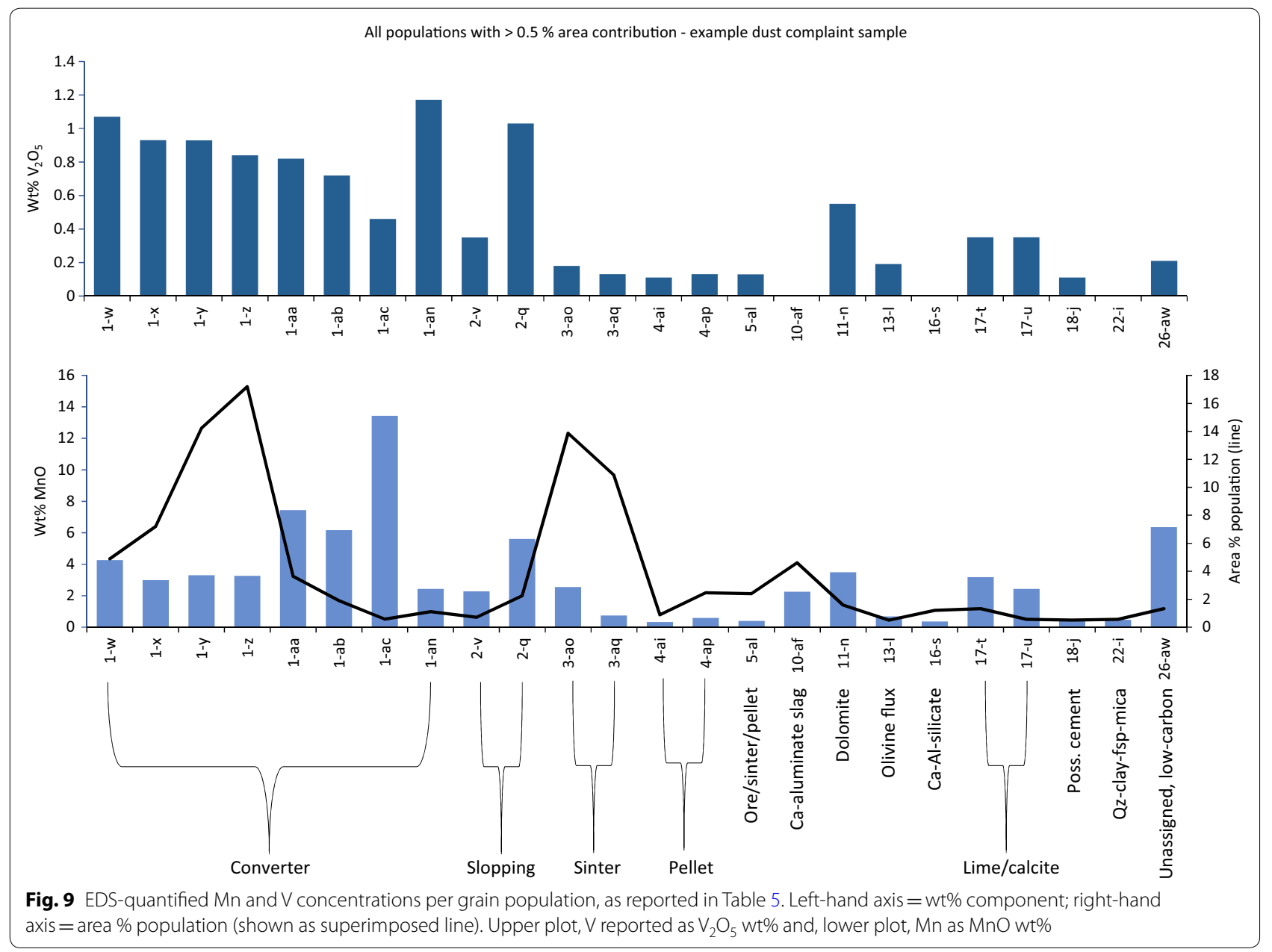

various environments is important to come to a realistic health risk assessment.

In the present study, dust particle populations are identified with mineralogy and phase chemistry specific to them, providing direct information on which dust sources contribute the potentially toxic elements mentioned above and on their mode of occurrence. $\mathrm{No} \mathrm{Pb}$ was detected in the EDS sum-spectra of any PARC group. $\mathrm{V}$ and $\mathrm{Mn}$, however, were clearly detected in specific dust particle populations.

Figure 9 compares the analysed $\mathrm{V}$ and $\mathrm{Mn}$ concentrations of dust grain populations with $>0.5$ area\% contribution to the example nuisance dust sample (Table 5). To shed light on the specific mineralogical phases containing high concentrations of these elements, Table 6 lists all PARC groups with concentrations $>0.5 \mathrm{wt} \% \mathrm{~V}$ reported as $\mathrm{V}_{2} \mathrm{O}_{5}$ and $>10 \mathrm{wt} \% \mathrm{Mn}$ reported as $\mathrm{MnO}$ quantified for their sum-spectra (collated per group per population, with full data tabulated in Additional file 1: F; note that listed populations in the table need not have a large bulk concentration of $\mathrm{V}$ or $\mathrm{Mn}$ if they contain only minor amounts of those PARC groups with the high concentrations).

Clearly, the highest bulk concentrations of $\mathrm{V}$ are measured in the populations associated with converter slag as well as slopping slag (also converter process derived). Significant concentrations are also measured in the grain populations associated with dolomite $\left(11-\mathrm{n}^{1}\right)$ and $\mathrm{Ca}$-(hydr)oxide/-carbonate (17-t, 17-u). Iron-ore sinter and pellet grain populations (source/material categories 3, 4 and 5) have much lower concentrations around detection limits, while no detectable concentration is measured in the Ca-aluminate slag population (10-af). Within the converter-slag grain populations with the highest overall $\mathrm{V}$ concentrations, the PARC groups with the highest $\mathrm{V}$-concentrations in the $\{\mathrm{Si}, \mathrm{Ca}\}(0.9-3.9 \mathrm{wt} \%$ $\left.\mathrm{V}_{2} \mathrm{O}_{5}\right)$ and $\{\mathrm{Al}, \mathrm{Ca}, \mathrm{Fe}\}\left(0.5-1.2 \mathrm{wt} \% \mathrm{~V}_{2} \mathrm{O}_{5}\right)$ groups, interpreted, respectively, as $\mathrm{C} 2 \mathrm{~S}$ and $\mathrm{C} 2(\mathrm{~A}, \mathrm{~F})$ and weathering

\footnotetext{
${ }^{1}$ Grain populations are labelled in this section together with their source/ material ID with the nomenclature: [source/material ID]-[population ID].
} 
Table 6 PARC groups and interpreted true mineralogical phases containing high $\mathbf{V}$ or $\mathrm{Mn}$ concentrations (thresholds given in table)

\begin{tabular}{|c|c|c|c|c|}
\hline Source/material ID & Short name & Area \% & PARC groups satisfying criteria & True phases (interpreted) \\
\hline \multicolumn{5}{|c|}{$V>0.5 \mathrm{wt} \%$ (reported as $\mathrm{V}_{2} \mathrm{O}_{5}$ ) in one or more PARC groups (after erosion filter) } \\
\hline 1 & Converter & 51.09 & $\begin{array}{l}\{\mathrm{Ca}\},\{\mathrm{S}, \mathrm{Ca}\},\{\mathrm{Al}, \mathrm{Si}, \mathrm{Ca}\},\{\mathrm{S}\},\{\mathrm{Mg}, \mathrm{Si}, \mathrm{Ca}\},\{\mathrm{Al}, \mathrm{Ca}\} \\
\quad\{\mathrm{Al}, \mathrm{Ca}, \mathrm{Fe}\},\{\mathrm{Si}, \mathrm{Ca}\},\{\mathrm{Mg}, \mathrm{Si}, \mathrm{Ca}, \mathrm{Fe}\}\end{array}$ & $\begin{array}{l}\mathrm{C} 2 \mathrm{~S}, \mathrm{C} 2(\mathrm{~A}, \mathrm{~F}) \text {, lime/portlandite/calcite, weath- } \\
\text { ering products of } \mathrm{C} 2 \mathrm{~S} \text { and } \mathrm{C} 2(\mathrm{~A}, \mathrm{~F})\end{array}$ \\
\hline 2 & Slopping & 2.97 & $\{\mathrm{Ca}\},\{\mathrm{Al}, \mathrm{Si}, \mathrm{Ca}\},\{\mathrm{S}\},\{\mathrm{Si}, \mathrm{Ca}\}$ & $\begin{array}{l}\text { C2S, lime/portlandite/calcite, Ca-Al-silicate, } \\
\text { weathering products of C2S }\end{array}$ \\
\hline 3 & Sinter & 24.73 & $\{\mathrm{~S}, \mathrm{Ca}\},\{\mathrm{Mg}, \mathrm{Fe}\},\{\mathrm{Si}, \mathrm{Ca}\}$ & $\mathrm{C} 2 \mathrm{~S}$, possibly spinel solution $(\mathrm{Mg}, \mathrm{Fe})(\mathrm{Fe}, \mathrm{V})_{2} \mathrm{O}_{4}$ \\
\hline 10 & Ca-aluminate slag & 5.08 & $\{\mathrm{Mg}, \mathrm{Al}, \mathrm{Si}, \mathrm{Ca}\},\{\mathrm{S}\},\{\mathrm{Si}, \mathrm{Ca}\}$ & $\mathrm{C} 2 \mathrm{~S}$ \\
\hline 11 & Dolomite & 1.58 & $\{\mathrm{Mg}, \mathrm{Ca}\}$ & $\begin{array}{l}\text { Dolomite residue-potentially reacted: } \\
\text { monoxide } \mathrm{CaO} \text { - and } \mathrm{MgO} \text {-rich solutions } \\
\text { with } \mathrm{V}(\text { ?) or with } \mathrm{C} 2(\mathrm{~A}, \mathrm{~F}) \text { and } \mathrm{C} 2 \mathrm{~S} \text { finely } \\
\text { intergrown in small quantities }\end{array}$ \\
\hline 25 & Carbon-rich other & 0.80 & $\{\mathrm{Ca}\}$ & Lime/portlandite/calcite, C2(A,F) \\
\hline 26 & Unassigned, low carbon & 1.33 & $\{\mathrm{Ca}\},\{\mathrm{Si}, \mathrm{Ca}\}$ & Lime/portlandite/calcite, C2S \\
\hline \multicolumn{5}{|c|}{$\mathrm{Mn}>10$ wt\% (reported as $\mathrm{MnO}$ ) in one or more PARC groups (after erosion filter) } \\
\hline 1 & Converter & 51.09 & $\begin{array}{l}\{\mathrm{Mg}\},\{\mathrm{Mg}, \mathrm{Fe}\},\{\mathrm{Si}, \mathrm{Ca}, \mathrm{Fe}\},\{\mathrm{Mg}, \mathrm{Ca}, \mathrm{Fe}\},\{\mathrm{Mg}, \\
\mathrm{Si}, \mathrm{Ca}, \mathrm{Fe}\}\end{array}$ & $\begin{array}{l}\text { Mg-wustite }(\mathrm{Mg}, \mathrm{Mn}, \mathrm{Fe}) \mathrm{O} \text {; oxidation products } \\
\text { of } \mathrm{Mg} \text {-wustite incl. spinel solution (magnet- } \\
\text { ite) }(\mathrm{Mg}, \mathrm{Mn}, \mathrm{Fe})(\mathrm{Fe}, \mathrm{Mn})_{2} \mathrm{O}_{4} \text {; lime }(\mathrm{Ca}, \mathrm{Mn}, \mathrm{Fe}) \mathrm{O} \text {, } \\
\text { portlandite and calcite }\end{array}$ \\
\hline 2 & Slopping & 2.97 & $\{\mathrm{Mg}, \mathrm{Fe}\}$ & Mg-wustite $\{\mathrm{Mg}, \mathrm{Mn}, \mathrm{Fe}) \mathrm{O}$ \\
\hline 3 & Sinter & 24.73 & $\{\mathrm{Mg}, \mathrm{Fe}\},\{\mathrm{Mn}\},\{\mathrm{Mg}, \mathrm{Ca}, \mathrm{Fe}\},\{\mathrm{Mn}, \mathrm{Fe}\}$ & $\begin{array}{l}\text { Mg-wustite }(\mathrm{Mg}, \mathrm{Mn}, \mathrm{Fe}) \mathrm{O} \text {, scarce } \mathrm{Mn} \text {-dom- } \\
\text { inated } \mathrm{Mn}-\mathrm{Fe}-\mathrm{oxide} \text {, magnetite (spinel) } \\
\text { solution }(\mathrm{Mg}, \mathrm{Mn}, \mathrm{Fe})(\mathrm{Fe}, \mathrm{Al})_{2} \mathrm{O}_{4}\end{array}$ \\
\hline 5 & Ore/sinter/pellet & 3.10 & $\{\mathrm{Ca}\}$ & Lime $\{\mathrm{Ca}, \mathrm{Mn}, \mathrm{Fe}) \mathrm{O} /$ portlandite \\
\hline 10 & Ca-aluminate slag & 5.08 & $\{\mathrm{Mg}, \mathrm{Al}\}$ & Spinel $(\mathrm{Mg}, \mathrm{Mn}) \mathrm{Al}_{2} \mathrm{O}_{4}$ \\
\hline 11 & Dolomite & 1.58 & $\{\mathrm{Mg}, \mathrm{Fe}\}$ & Mg-wustite $(\mathrm{Mg}, \mathrm{Mn}, \mathrm{Fe}) \mathrm{O}$ \\
\hline 22 & Qz-clay-fsp-mica & 0.64 & $\{\mathrm{Si}, \mathrm{Ca}\}$ & $\begin{array}{l}\text { Possible pyroxene or other natural rock- } \\
\text { forming mineral }\end{array}$ \\
\hline 26 & Unassigned, low carbon & 1.33 & $\{\mathrm{Si}\},\{\mathrm{Mn}\},\{\mathrm{Si}, \mathrm{Mn}\},\{\mathrm{Al}, \mathrm{Si}, \mathrm{Mn}\}$ & $\begin{array}{l}\text { Mn-dominated Mn-Fe-oxide, Mn-rich silicate } \\
\text { phases }\end{array}$ \\
\hline
\end{tabular}

Full tabulated EDS analyses given in Additional file 1: $F$

products of these. This is consistent with earlier studies showing a high affinity of these phases for V [35]. Significant concentrations of $\mathrm{V}(0.9-1.5 \mathrm{wt} \%)$ are also measured in the $\{\mathrm{Si}, \mathrm{Ca}\}$ group-interpreted as $\mathrm{C} 2 \mathrm{~S}$-in the sinter-related grain populations, while the bulk concentration of $\mathrm{V}$ in these populations is much lower than in the converter-related populations. This corresponds with a much lower abundance of $\mathrm{C} 2 \mathrm{~S}$ in the sinter material compared to converter-slag material. Other grain populations also contain individual PARC groups-hence specific phases or phase intergrowths-with $\mathrm{V}$ concentration of $\mathrm{V}_{2} \mathrm{O}_{5}>0.5 \mathrm{wt} \%$ (listed in Table 6), including potentially other phases besides $\mathrm{C} 2 \mathrm{~S}$ and $\mathrm{C} 2(\mathrm{~A}, \mathrm{~F})$, though the $\mathrm{V}$ concentration in the bulk grain populations is relatively low.

The grain populations with the highest measured concentrations of $\mathrm{Mn}$ are those attributed to converter slag and rich in $\mathrm{C} 2(\mathrm{~A}, \mathrm{~F})$ (1-aa and 1-ab) and especially the Mg-wustite-rich population (1-ac). Notably, the most Ca-ferrite (SFCA-)rich iron-ore sinter grain population (3-ao) has a similar Mn concentration to the volumetrically dominant C2S/C3S-rich converter-slag populations (1-y and 1-z), while the other sinter- and pellet-related populations have much lower Mn concentrations. In the converter-slag grain populations, the highest concentrations of $\mathrm{Mn}$ are found in the PARC group $\{\mathrm{Mg}$, $\mathrm{Fe}$ ) with $13-27 \mathrm{wt} \% \mathrm{Mn}$ reported as $\mathrm{MnO}$, interpreted as $\mathrm{Mg}-\mathrm{Mn}$-wustite, $(\mathrm{Mg}, \mathrm{Mn}, \mathrm{Fe}) \mathrm{O}$ and finely intergrown oxidation products of this, including spinel solid solution $(\mathrm{Mg}, \mathrm{Mn}, \mathrm{Fe})(\mathrm{Fe}, \mathrm{Mn})_{2} \mathrm{O}_{4}$. QXRD analyses of the reference converter-slag dust samples (Fig. 4) show that these contain both wustite and magnetite (spinel solid solution) but no direct estimate can be made with QXRD of the mutual proportions of these in the converter-slag dust particle populations within the nuisance dust sample since the latter contains a mixture of populations and abundant magnetite from iron-ore, sinter and pellets.

In the case of the sinter population (3-ao), an explanation is required for the relatively high bulk Mn concentration compared both with the other iron-ore-related grain populations and the chemistry of bulk sinter material 


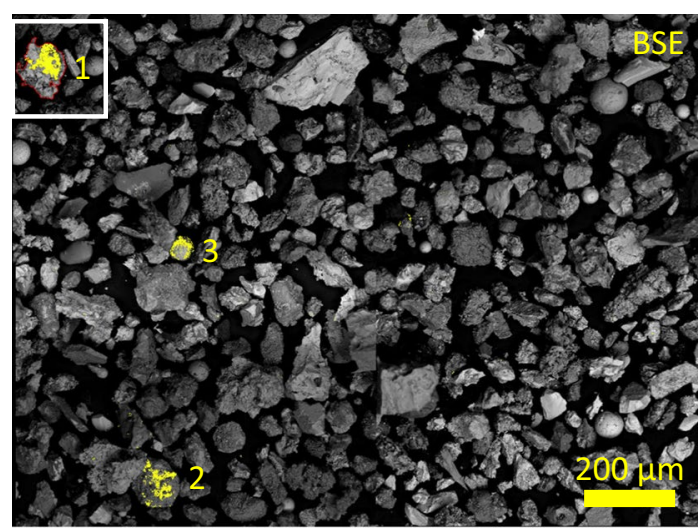

\section{a Distribution of \\ PARC groups \\ $\{ \pm S, \pm \mathrm{Ca}, \mathrm{Mn}, \pm \mathrm{Fe}\}$}
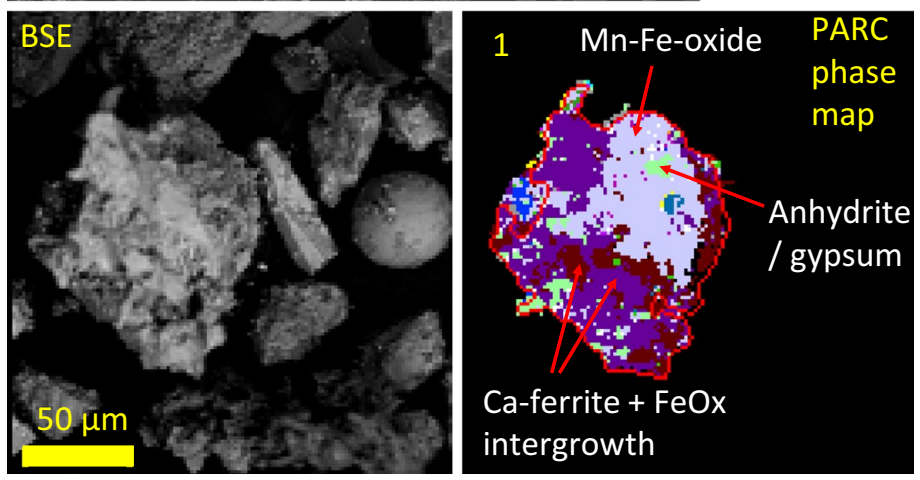

b Grain 1 details

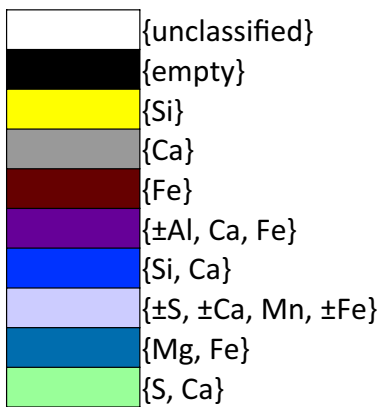

Fig. 10 a Region of interest in SEM-BSE image of nuisance dust example (Fig. 1) showing distribution of PARC groups $\{ \pm \mathrm{S}, \pm \mathrm{Ca}, \mathrm{Mn}, \pm \mathrm{Fe}\}$ highlighted yellow. Note localised concentrations of these pixels in grains 1-3. Grains 1 and 2 are classified as population ao (iron-ore sinter rich in Ca-ferrites), grain 3 as population aw (unassigned, low empty spectra; Table 3). b region of interest from the corresponding PARC phase map, showing microstructural detail of sinter grain (1) with an abundance of Mn-rich pixels (PARC groups $\{\mathrm{Mn}\},\{\mathrm{Mn}, \mathrm{Fe}\},\{\mathrm{Ca}, \mathrm{Mn}, \mathrm{Fe}\}$ ). Red outline in phase map marks perimeter of grain as defined during grain segmentation. Showing phase map for grain 1 only

(which typically contains c. 0.1-0.5 wt\% MnO depending on the ore blend). This grain population contains a low but clearly detectable presence of PARC groups (listed in Table 5) with Mn concentrations greatly exceeding those of any groups encountered in the converter-slag grain populations. Detailed inspection of these Mn-rich pixel groups' distribution in the PARC phase map (Fig. 10a) reveals two individual grains (annotations 1 and 2), classified as sinter (3-ao), containing a high abundance of $\{ \pm \mathrm{S}, \pm \mathrm{Ca}, \mathrm{Mn}, \pm \mathrm{Fe}\}$ pixels together with the groups typically abundant in this grain population. The observed microstructural relations of the PARC groups (shown in Fig. 10b for grain 1) imply either an intergrowth or covering layer of $\mathrm{Mn}$-Fe-oxide (or hydroxide/carbonate) in or on sinter grains comprising dominantly $\mathrm{FeOx}$ and $\mathrm{Ca}-$ ferrites with minor Ca-silicate (C2S). The $\{\mathrm{Mn}\}$ group for this sinter population contains c. $83 \mathrm{wt} \% \mathrm{Mn}$ reported as $\mathrm{MnO}$, together with $\mathrm{Fe}$ and minor $\mathrm{Ca}, \mathrm{Si}$ and $\mathrm{S}$ (the latter likely mixed signal from $\mathrm{Ca}$-ferrite, $\mathrm{Ca}$-silicate and $\mathrm{Ca}$ sulphate). Examining the reference sinter dust 1, a small number of grains were found with a high abundance of $\{\mathrm{Mn}\}$ pixels with similar spectral signature as in the nuisance dust sample. From this, we infer that extremely scarce particles containing $\mathrm{Mn}-\mathrm{Fe}$-oxide or potentially hydroxide/carbonate may be associated with iron-ore sinter dust. The precise mineralogical identity, and speciation of $\mathrm{Mn}$, of this phase is not yet determined as it is present in such low abundance that it is undetected by XRD analysis. Most sinter dust particles contain much less $\mathrm{Mn}(<1 \mathrm{wt} \%)$, as reflected in the composition of the sinter grain population 3-aq. Besides the scarce $\mathrm{Mn}-\mathrm{Fe}-$ oxide phase identified, the $\mathrm{Mn}$ in the sinter grain populations is housed in a more dilute form in $\mathrm{Fe}_{3} \mathrm{O}_{4}$-dominated spinel solid solution (magnetite) appearing as the PARC group $\{\mathrm{Fe}\}$, with Mn content c. $0.3-0.7 \mathrm{wt} \%$ (reported as $\mathrm{MnO}$ ), and in Ca-ferrite phases (dominantly SFCA) with c. $1.0-1.3 \mathrm{wt} \%$.

To summarise, applying the PARC methodology indicates that the most V-rich material in the example nuisance dust sample is derived from steelmaking converter slag (and process) and that it is housed in dilute form (solid solution) in the phases $\mathrm{C} 2 \mathrm{~S}$ and brownmillerite, as well as weathering/alteration products of these. Similarly, the same material derived from converter slag has 
the highest general concentrations of $\mathrm{Mn}$, housed chiefly in the $\mathrm{Mg}-\mathrm{Fe}$-oxide solid solution phases $\mathrm{Mg}$-wustite $(\mathrm{Mg}, \mathrm{Mn}, \mathrm{Fe}) \mathrm{O}$ and magnetite $(\mathrm{Mg}, \mathrm{Mn}, \mathrm{Fe})(\mathrm{Fe}, \mathrm{Mn})_{2} \mathrm{O}_{4}$. Both $\mathrm{Mn}$ and $\mathrm{V}$ are known to be heavily concentrated in converter slag during the production of steel from original raw materials (ores, fluxes, coal). An unexpectedly high Mn concentration detected in one of the ironore sinter grain populations flagged up the presence of scarce particles $(<<0.1 \%$ area contribution) containing abundant $\mathrm{Mn}-\mathrm{Fe}$-oxide (or hydroxide/carbonate), where this phase contains at least c. $80 \mathrm{wt} \% \mathrm{Mn}$ reported as $\mathrm{MnO}$. Further investigation is required to fully pin down the identity of this phase but it is clearly associated with material from the iron-ore sintering process and present in very low abundance in sinter reference materials.

This example illustrates how with a micro-analysis approach-based on treating individual particles and particle populations in terms of their constituent mineral chemistry-it is possible to investigate simultaneously the mode of occurrence, distribution and origin (source) of potentially toxic elements occurring in bulk nuisance dust material. While bulk chemical analyses of nuisance dust may flag up any elevated concentrations of potentially toxic elements in the bulk material, an adequate characterisation must go beyond this and provide at minimum the type of information shown here on constituent particles' mineralogy and phase chemistry to support toxicological evaluation, establish provenance and mitigate emissions at source.

\section{Conclusions}

A robust method has been developed to quantitatively analyse the provenance, mineralogical and chemical attributes of the constituent particles in $(10-100 \mu \mathrm{m})$ coarse airborne nuisance dust deriving from the integrated steelworks of Tata Steel IJmuiden, the Netherlands. The method involves detecting individual dust particles (grains) in a sample and sorting these into populations based on the mineralogical characteristics of their surfaces as analysed with SEM-EDS spectral imaging and processing with PARC software. The abundances, and mineralogical and chemical characteristics, of each sample's grain populations are then quantitatively analysed. QXRD provides independent complementary analysis of bulk sample mineralogy. A total of 48 grain populations have been defined based on comparison of nuisance dust grains with the reference characteristics or samples of 23 source materials of industrial (steelworks) (14), urban (3), natural (2) and potentially ambiguous origin (4), while a further two distinct materials are identified whose origin is not known. The method is demonstrably successful at distinguishing several key source materials derived from iron-ore agglomeration and the steelmaking converter process. Applying the characterisation method to a nuisance dust complaint sample from the town of Wijk aan Zee with a very high contribution from several verified source materials attributable to the steelworks, we demonstrate that detailed information can be gleaned pertaining to provenance and potential environmental/health risks associated with the encountered dust particles. The occurrence of potentially toxic elements can be traced to specific dust particle populations of known origin and the mode of occurrence in (mineral) phases can be identified to support robust toxicological evaluation. Specifically, for the nuisance dust sample shown, the most V-rich material is derived from steelmaking converter slag (and process) and is housed in dilute form (solid solution) in the phases $\mathrm{C} 2 \mathrm{~S}$ and brownmillerite, and in weathering/alteration products of these. Similarly, the same material derived from converter slag has the highest general concentrations of $\mathrm{Mn}$, housed chiefly in the $\mathrm{Mg}-\mathrm{Fe}$-oxide solid solution phases $\mathrm{Mg}$-wustite $((\mathrm{Mg}, \mathrm{Mn}, \mathrm{Fe}) \mathrm{O})$ and magnetite $((\mathrm{Mg}, \mathrm{Mn}, \mathrm{Fe})$ $\left.(\mathrm{Fe}, \mathrm{Mn})_{2} \mathrm{O}_{4}\right)$. The developed method is currently being applied to characterise larger sample sets of nuisance dust in the surroundings of the integrated steelworks of IJmuiden to aid efforts to mitigate nuisance dust emissions at source and provide more detailed and appropriate information for toxicological evaluation than that available from solely bulk chemical analyses. Moreover, the characterisation approach also helps address the lack of adequate monitoring options for deposits of nuisance dust from integrated steel production, necessary to evaluate the relationship between deposition and monitored emissions that are regulated by the European Industrial Emissions Directive and by local permits based on this legislation.

\section{Supplementary information}

Supplementary information accompanies this paper at https://doi. org/10.1186/s12302-020-00414-6.

Additional file 1. Supplementary information is provided in the following additional files (prefixed with 'additional file'): (A) fully indexed diffraction patterns and tabulated quantitative results for QXRD analyses; (B) complete details of filters used in grain population classification model; (C) tabulated data plotted in Fig. 6; (D)-(i) full tabulated data for PARC group and grain population area percentages per sample, and (D)-(ii) original SEM-BSE and PARC-generated imagery for all samples (files labelled by sample name and, where relevant, by image type); (E) tabulated data as plotted in Fig. 7; (F) tabulated quantitative SEM-EDS analyses as applicable to sections "Quantified chemistry of grain populations" and "Mode of occurrence of identified potentially toxic elements - V,$M n$ " (PARC groupand grain population sum-spectra for example nuisance dust dataset).

\section{Abbreviations}

BAT: Best available techniques; BREF: Best available techniques reference document; BSE: Back-scattered electron; EDS: Energy-dispersive spectrometry; LOM: Light optical microscopy; PARC: PhAse Recognition and Characterisation (software); PM10/PM2.5: Particulate material with diameter $<10$ or $2.5 \mu \mathrm{m}$; 
QXRD: Quantitative X-ray diffraction; SEM: Scanning electron microscopy; SI: Spectral imaging; SFCA: Silico ferrite(s) of calcium and aluminium; TSP: Total suspended particles; Note on cement chemist notation: Several phases are referred to in this article by their nominal chemical formulae expressed using this notation form, where $\mathrm{C}=\mathrm{CaO}, \mathrm{M}=\mathrm{MgO}, \mathrm{A}=\mathrm{Al}_{2} \mathrm{O}_{3}, \mathrm{~S}=\mathrm{SiO}_{2}, \mathrm{~W}=\mathrm{FeO}$ and $\mathrm{F}=\mathrm{Fe}_{2} \mathrm{O}_{3}$. E.g. $\mathrm{C} 2 \mathrm{~S}=2 \mathrm{CaO} \cdot \mathrm{SiO}_{2}=\mathrm{Ca}_{2} \mathrm{SiO}_{4}=$ di-calcium silicate. To avoid confusion with standard chemical formulae, subscripts are not used in the cement chemist notation here.

\section{Acknowledgements}

The authors wish to acknowledge Tata Steel for the generous amounts of time and resources allowed for the development of the methodology and its application to nuisance dust.

\section{Authors' contributions}

SvdL, CVH, JS, KS, EMK, made substantial contributions to the conception and design of the work; KS and EMK developed PARC group model; IS developed grain population model; Field sampling responsibility TdJ, TdB. Environmental Legislative context: RV; The acquisition, analysis, and interpretation of data responsibility for XRD (SM), for SEM-SI (CVH, JS, KS, FvdD) and Optical Micr. (FvdD); PARC software was created by MdR; SvdL, CVH, JS, KS, SM, TdB, RV have drafted the work or substantively revised it. All authors read and approved the final manuscript.

\section{Funding}

This study has been entirely funded by Tata Steel Europe.

\section{Availability of data and materials}

All data generated or analysed during this study are included in this published article [and its Additional files] or are available from the corresponding author on reasonable request.

\section{Ethics approval and consent to participate Not applicable.}

\section{Consent for publication}

Not applicable.

\section{Competing interests}

The authors declare that they have no competing interests.

\begin{abstract}
Author details
${ }^{1}$ Tata Steel Europe, P.O. Box 10.000, 1970 CA IJmuiden, The Netherlands. 2 Department of the Built Environment, Eindhoven University of Technology, P.O. Box 513, 5600 MB Eindhoven, The Netherlands. ${ }^{3}$ 2SEE Technology, Utrechtsestraatweg 23A, 3445 AL Woerden, The Netherlands. ${ }^{4}$ Present Address: Aurubis AG, Hovestraße 50, 20539 Hamburg, Germany.
\end{abstract}

Received: 8 June 2020 Accepted: 21 September 2020 Published online: 14 October 2020

\section{References}

1. Williams WB (2014) Source apportionment and dispersion mapping of fugitive dust using directional passive monitors. Dissertation, University of Portsmouth.

2. Regtuit HE, de Ruiter CJ, Vrins ELM, Hofschreuder P, Oeseburg F, Benschop FM (1990) The tunnel impactor. A multiple inertial impactor for coarse aerosol. J Aerosol Sci 21:919-933. https://doi.org/10.1016/00218502(90)90162-Q

3. European Parliament and Council (2008) Directive 2008/50/EC of the European Parliament and Council of 21 May 2008 on Ambient Air Quality and Cleaner Air for Europe. Off J Eur Union L 152:1-44

4. European Environment Agency (2011) The application of models under the European Union's Air Quality Directive: a technical reference guide. https://www.eea.europa.eu/publications/fairmode. Accessed 15 Sept 2020

5. European Standard: EN 12341:2014 Ambient air. Standard gravimetric measurement method for the determination of PM10 or PM2.5 mass concentration of suspended particulate matter. 2014.
6. United States Environmental Protection Agency (2019) Integrated Science Assessment for Particulate Matter. https://cfpub.epa.gov/ncea/isa/ recordisplay.cfm?deid=347534\#tab-3. Accessed 15 Sept 2020.

7. Occupational Environmental Health Team-World Health Organisation (1999) Hazard prevention and control in the work environment: airborne dust. World Health Organization. https://www.who.int/occupation al_health/publications/airdust/en/. Accessed 15 Sept 2020.

8. Cheng YS (2014) Mechanisms of pharmaceutical aerosol deposition in the respiratory tract. AAPS PharmSciTech 15:630-640. https://doi. org/10.1208/s12249-014-0092-0

9. Solomon A, Gehr P, Bennett DH, Phalen RF, Mendez LB, Rothen-Rutishauser B, Clift M, Brandenberger C, Mühlfeld C (2012) Macroscopic to microscopic scales of particle dosimetry: from source to fate in the body. Air Qual Atmos Heal. https://doi.org/10.1007/s11869-011-0167-y

10. Kim RY, Yoon JK, Kim TS, Yang JE, Owens G, Kim KR (2015) Bioavailability of heavy metals in soils: definitions and practical implementation-a critical review. Environ Geochem Health. https://doi.org/10.1007/s1065 3-015-9695-y

11. U.S. Environmental Protection Agency (2008) Integrated science assessment for oxides of nitrogen, oxides of sulfur, and particulate matterecological criteria. EPA/600/R-08/082F. https://cfpub.epa.gov/ncea/isa/ recordisplay.cfm?deid=201485. Accessed 15 Sept 2020.

12. Scrogi K (2007) Monitoring of environmental exposure to polycyclic aromatic hydrocarbons: a review. Env Chem Lett 5:169-195. https://doi. org/10.1007/s10311-007-0095-0

13. Hleis D, Fernández-Olmo I, Ledoux F, Kfoury A, Courcot L, Desmonts T, Courcot D (2013) Chemical profile identification of fugitive and confined particle emissions from an integrated iron and steelmaking plant. J Hazard Mater 250-251:246-255. https://doi.org/10.1016/j.jhazm at.2013.01.080

14. Beddows DCS, Harrison RM (2017) Identification of specific sources of airborne particles emitted from within a complex industrial (steelworks) site. Atmos Environ 183:122-134. https://doi.org/10.1016/j.atmos env.2018.03.055

15. Ferranti EJS, Fryer M, Sweetman AJ, Garcia MAS, Timmis RJ (2014) Fieldtesting a new directional passive air sampler for fugitive dust in a complex industrial source environment. Environ Sci Process Impacts. https:// doi.org/10.1039/c3em00525a

16. European Commission (2013) IPPC best available techniques (BAT) reference document for iron and steel production. Industrial Emissions Directive 2010/75/EU. doi: https://doi.org/10.2791/97469.

17. Council of the European Union (1996) Council Directive 96/61/EC of 24 September 1996 concerning integrated pollution prevention and control. Off J Eur Union L 257:26-40

18. European Commission (2001) IPPC reference document on best available techniques in the ferrous metals processing industry. https://eippcb.jrc. ec.europa.eu/sites/default/files/2019-11/fmp_bref_1201.pdf. Accessed 15 Sept 2020.

19. The European Commision (2015) Commission Directive (EU) 2015/1480 of 28 August 2015 amending several annexes to Directives 2004/107/EC and 2008/50/EC of the European Parliament and of the Council laying down the rules concerning reference methods, data validation and location of sampling points for the assessment of ambient air quality. Off J Eur Union L 226:4-11

20. European Commission (2006) IPPC reference document on best available techniques on emission from storage. https://eippcb.jrc.ec.europa.eu/ sites/default/files/2019-11/esb_bref_0706.pdf. Accessed 15 Sept 2020.

21. European Pollutant Release and Transfer Register (E-PRTR). https://prtr. eea.europa.eu/\#/facilitylevels. Accessed 15 Sept 2020.

22. Tata Steel Sustainability Report FY18/19. Available via https://omgeving tatasteel.nl/duurzaamheid/. Accessed 15 Sept 2020.

23. Watson JG, Chow JC, Pace TG (2000) Fugitive dust emissions. In: Davis WT (ed) Air polution engineering manual, 2nd edn. Wiley, New York

24. Arndt J, Deboudt K, Anderson A, Blondel A, Eliet S, Flament P, Fourmentin M, Healy RM, Savary V, Setyan A, Wenger JC (2016) Scanning electron microscopy-energy dispersive $X$-ray spectrometry (SEM-EDX) and aerosol time-of-flight mass spectrometry (ATOFMS) single particle analysis of metallurgy plant emissions. Environ Pollut 210:9-17. https://doi. org/10.1016/j.envpol.2015.11.019

25. Mazzei F, D'Alessandro A, Lucarelli F, Marenco F, Nava S, Prati P, Valli G, Vecchi R (2006) Elemental composition and source apportionment of 
particulate matter near a steel plant in Genoa (Italy). Nucl Instrum Methods Phys Res Sect B Beam Interact with Mater Atoms 249:548-551. https ://doi.org/10.1016/j.nimb.2006.03.050

26. Krueger BJ, Grassian VH, Cowin JP, Laskin A (2004) Heterogeneous chemistry of individual mineral dust particles from different dust source regions: The importance of particle mineralogy. Atmos Environ 38:6253-6261. https://doi.org/10.1016/j.atmosenv.2004.07.010

27. Peijnenburg WJGM, Posthuma L, Eijsackers HJP, Allen HE (1997) A conceptual framework for implementation of bioavailability of metals for environmental management purposes. Ecotoxicol Environ Saf 37:163-172. https://doi.org/10.1006/eesa.1997.1539

28. van Hoek C, Small J, van der Laan S (2016) Large-area phase mapping using PhAse Recognition and Characterization (PARC) software. Microsc Today 24:12-21. https://doi.org/10.1017/s1551929516000572

29. Goldstein Jl, Newbury DE, Michael JR, Ritchie NWM, Scott JHJ, Joy DC (2017) Scanning electron microscopy and X-ray microanalysis, 4th edn. Springer, New York

30. Inorganic Crystal Structure Database. https://icsd.products.fiz-karlsruhe. de/. Accessed 15 Sept 2020.

31. Legland D, Arganda-Carreras I, Andrey P (2016) MorphoLibJ: integrated library and plugins for mathematical morphology with ImageJ.
Bioinformatics 32:3532-3534. https://doi.org/10.1093/bioinformatics/ btw413

32. Malshe VC, Sickchi M (2002) Basics of paint technology part I. 1st ed (2nd reprint 2004). Malshe VC, Mumbai.

33. Campbell DH (1999) Microscopical examination and interpretation of portland cement and clinker, 2nd edn. Portland Cement Asscociation, Illinois

34. Rijksinstituut voor Volksgezondheid en Milieu (RIVM) (2019) Inschatting gezondheidsrisico's grafietregen Wijk aan Zee [in Dutch. Trans. Health risk assessment graphite rains Wijk aan Zee]. https://www.rivm.nl/ documenten/inschatting-gezondheidsrisicos-grafietregen-wijk-aan-zee. Accessed 17 Apr 2020.

35. Chaurand P, Jérôme R, Briois V, Salome M, Proux O, Nassif V, Olivi L, Susini J, Hazemann J-L, Bottero J-Y (2007) New methodological approach for the vanadium $\mathrm{K}$-edge $\mathrm{X}$-ray absorption near-edge structure interpretation: application to the speciation of vanadium in oxide phases from steel slag. J Phys Chem B 111:5101-5110. https://doi.org/10.1021/jp063186i

\section{Publisher's Note}

Springer Nature remains neutral with regard to jurisdictional claims in published maps and institutional affiliations.

\section{Submit your manuscript to a SpringerOpen ${ }^{\odot}$ journal and benefit from:}

- Convenient online submission

- Rigorous peer review

- Open access: articles freely available online

- High visibility within the field

- Retaining the copyright to your article

Submit your next manuscript at $\gg$ springeropen.com 